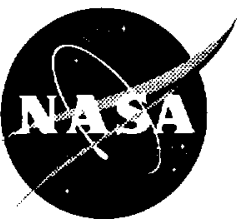

\title{
The Effect of Interface Roughness and Oxide Film Thickness on the Inelastic Response of Thermal Barrier Coatings to Thermal Cycling
}

Marek-Jerzy Pindera

University of Virginia, Charlottesville, Virginia

Jacob Aboudi

Tel-Aviv University, Ramat-Aviv, Israel

Steven M. Arnold

Glenn Research Center, Cleveland, Ohio 
Since its founding, NASA has been dedicated to the advancement of aeronautics and space science. The NASA Scientific and Technical Information (STI) Program Office plays a key part in helping NASA maintain this important role.

The NASA STI Program Office is operated by Langley Research Center, the Lead Center for NASA's scientific and technical information. The NASA STI Program Office provides access to the NASA STI Database, the largest collection of aeronautical and space science STI in the world. The Program Office is also NASA's institutional mechanism for disseminating the results of its research and development activities. These results are published by NASA in the NASA STI Report Series, which includes the following report types:

- TECHNICAL PUBLICATION. Reports of completed research or a major significant phase of research that present the results of NASA programs and include extensive data or theoretical analysis. Includes compilations of significant scientific and technical data and information deemed to be of continuing reference value. NASA's counterpart of peerreviewed formal professional papers but has less stringent limitations on manuscript length and extent of graphic presentations.

- TECHNICAL MEMORANDUM. Scientific and technical findings that are preliminary or of specialized interest, e.g., quick release reports, working papers, and bibliographies that contain minimal annotation. Does not contain extensive analysis.

- CONTRACTOR REPORT. Scientific and technical findings by NASA-sponsored contractors and grantees.
- CONFERENCE PUBLICATION. Collected papers from scientific and technical conferences, symposia, seminars, or other meetings sponsored or cosponsored by NASA.

- SPECIAL PUBLICATION. Scientific, technical, or historical information from NASA programs, projects, and missions, often concerned with subjects having substantial public interest.

- TECHNICAL TRANSLATION. Englishlanguage translations of foreign scientific and technical material pertinent to NASA's mission.

Specialized services that complement the STI Program Office's diverse offerings include creating custom thesauri, building customized data bases, organizing and publishing research results ... even providing videos.

For more information about the NASA STI Program Office, see the following:

- Access the NASA STI Program Home Page at http://www.sti.nasa.gov

- E-mail your question via the Internet to help@sti.nasa.gov

- Fax your question to the NASA Access Help Desk at (301) 621-0134

- Telephone the NASA Access Help Desk at (301) 621-0390

- Write to: NASA Access Help Desk NASA Center for AeroSpace Information 7121 Standard Drive Hanover, MD 21076 
NASA/TM-1999-209770

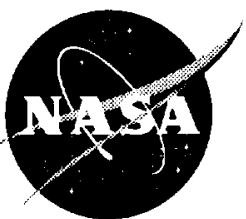

\section{The Effect of Interface Roughness and Oxide Film Thickness on the Inelastic Response of Thermal Barrier Coatings to Thermal Cycling}

Marek-Jerzy Pindera

University of Virginia, Charlottesville, Virginia

Jacob Aboudi

Tel-Aviv University, Ramat-Aviv, Israel

Steven M. Arnold

Glenn Research Center, Cleveland, Ohio

National Aeronautics and

Space Administration

Glenn Research Center 


\section{Acknowledgments}

The first two authors gratefully acknowledge the support provided by the NASA Glenn Research Center through the grant NASA NAG3-1377. The authors also thank Dr. Freborg for his comments on the original version of this report.

Available from

NASA Center for Aerospace Information

7121 Standard Drive

Hanover, MD 21076

Price Code: A03
National Technical Information Service 5285 Port Royal Road Springfield, VA 22100 Price Code: A03 


\title{
The Effect of Interface Roughness and Oxide Film Thickness on the Inelastic Response of Thermal Barrier Coatings to Thermal Cycling
}

\author{
Marek-Jerzy Pindera \\ University of Virginia, Charlottesville, VA 22903, USA \\ Jacob Aboudi \\ Tel-Aviv University, Ramat-Aviv 69978, ISRAEL \\ Steven M. Arnold \\ NASA Glenn Research Center, Cleveland, OH 44135, USA
}

\begin{abstract}
The effects of interfacial roughness and oxide film thickness on thermally-induced stresses in plasma-sprayed thermal barrier coatings subjected to thermal cycling are investigated using the recently developed higher-order theory for functionally graded materials. The higher-order theory is shown to be a viable alternative to the finite-element approach, capable of modeling different interfacial roughness architectures in the presence of an aluminum oxide layer and capturing the high stress gradients that occur at the top coat/bond coat interface. The oxide layer thickness is demonstrated to have a substantially greater effect on the evolution of residual stresses than local variations in interfacial roughness. Further, the location of delamination initiation in the top coat is predicted to change with increasing oxide layer thickness. This result can be used to optimize the thickness of a pre-oxidized layer introduced at the top coat/bond coat interface in order to enhance TBC durability as suggested by some researchers. The results of our investigation also support a recently proposed hypothesis regarding delamination initiation and propagation in the presence of an evolving bond coat oxidation, while pointing to the importance of interfacial roughness details and specimen geometry in modeling this phenomenon.
\end{abstract}

\section{INTRODUCTION}

Many factors may affect the durability of ceramic thermal barrier coatings (TBCs). These include the thermoelastic and viscoplastic parameters controlling the response of the individual constituents (i.e., the top coat, bond coat and substrate, see Fig. 1), bond coat/top coat interface roughness and strength, bond coat oxidation, top coat microstructure (which depends on the fabrication process [1]), substrate curvature, and imposed thermal load profiles. Each of these factors influences in a different manner the internal stresses induced in the individual constituents during service conditions, leading to potentially different failure modes [2,3]. A thorough understanding of 
the influence of each of these factors separately, as well as their interaction, is therefore essential in developing guidelines for the design of durable TBCs. This requires the development of sufficiently comprehensive analytical and/or numerical models capable of accurately assessing the importance of the above factors on the evolution of internal stresses during service conditions.

Early experimental investigations into failure mechanisms of plasma-sprayed TBCs conducted by Miller and Lowell [4] identified delamination at (or just above) the top coat/bond coat interface as the primary failure mode, ultimately leading to spallation of the coating. The failure mechanism was hypothesized to involve residual stresses induced into the coating during the cooldown stage of a thermal cycle due to the thermal expansion mismatch between the top coat and the bond coat. The initiation of the failure process was shown to be substantially influenced by the formation of a thin oxide film at the top coat/bond coat interface during exposure to elevated temperatures, and based on the observed location of delamination the interface's irregularity was thought to play a role. In order to better understand the influence of bond coat/top coat roughness and bond coat oxidation on thermally-induced stresses in plasma-sprayed TBCs, and thus the observed spallation-type failure modes, finite-element investigations were conducted by Chang et al. $[5,6,7,8]$ on a model cylindrical TBC geometry with a top coat/bond coat interface varying sinusoidally in the circumferential direction at a fixed radius from the cylinder's center. These studies demonstrated the evolution of a significant radial stress component at the top coat/bond coat interface upon cooldown, which became tensile at the wavy interface's crest. Incorporation of plasticity into the finite-element analysis decreased the magnitude of the radial stress, while introduction of an oxide layer between the top coat and the bond coat produced a change in the sign of this stress along the oxide layer/top coat interface. Based on the finite-element results, a model was proposed for oxidation-induced coating failure in plasma-sprayed coatings with rough interfaces. However, validation of the proposed model required the incorporation of all the features investigated separately into a unified model, including more realistic thermal loading, appropriate inelastic models for the constituent phases, oxide layer evolution and crack growth.

The results of similar, but more realistic, finite-element analyses, addressing the influence of bond coat/top coat interface roughness and bond coat oxidation on thermally induced stresses in plasma-sprayed ceramic coatings on cylindrical specimens, were recently reported in a sequence of papers by Ferguson et al. [9], Petrus and Ferguson [10] and Freborg et al. [11]. In these studies, cyclic thermal loading that closely simulated actual in-service thermal exposure was employed, oxide layer growth was modeled explicitly, and a creep model was used for the inelastic behavior of the TBC constituents to account for the actual time-dependent response at elevated temperatures. The results indicate the evolution of a non-zero stress component normal to the interface during cyclic thermal loading. Due to stress relaxation during the hold period of a heatup-hold-cooldown thermal cycle, this stress component becomes tensile at the interface's crest upon cooldown. The presence of this stress component correlates well with the observed horizontal cracks at or just above the interfacial crests which have been demonstrated previously to produce spallation-type failures in plasma-sprayed TBCs. Oxidation of the bond coat was shown to affect the stress distribution normal to the bond coat/top coat interface in a manner that accelerates the spallation process.

In this paper, we report the results of an investigation which addresses similar issues but from a somewhat different perspective. First, we consider a flat TBC system shown in Fig. 1(a) that remains in a generalized plane strain state under the imposed spatially uniform cyclic thermal loading which simulates uniformly-applied furnace thermal cycling. Experiments on a similar geometry under this type of thermal loading were recently conducted by Koolloos and Houben [12]. Thus we eliminate any effects due to curvature that may cause additional radial stresses normal to the bond 
coat/top coat interface. This allows us to investigate the stresses induced strictly by the interfacial waviness. Second, we consider a periodically varying wavy interface between the top and bond coats whose waveform consists of two sine waves which are mirror images of each other as shown in Fig. 1(a), in contrast with the single sine wave representation employed in the finite-element studies discussed above (i.e., Ref. [5-11]). The double sine wave contains cusps and thus is a more realistic representation of the locally irregular interfacial features produced by the plasma-spray process than the smooth single sine wave representation [3]. To investigate the effect of interfacial roughness on the stress field during the applied thermal cycle, the trough amplitude is varied (with the crest amplitude fixed) to produce low, standard and high degrees of interfacial roughness. The chosen model geometries allow one to investigate disturbances in the stress field produced by local interfacial roughness irregularities observed in plasma-sprayed coatings. Due to the periodic nature of the TBC system's architecture, the analysis of thermally-induced stress fields is performed on the repeating cross-section element shown in Fig. 1(b) under constraints which simulate generalized plane strain deformation and take advantage of the symmetry considerations.

In addition, an oxide layer is introduced between the top coat and the bond coat of the standard interface roughness geometry to investigate its effect on the stress field. In this investigation, we do not attempt to simulate the growth of this oxide layer as a function of time as will be discussed in more detail later, in contrast with the work of Ferguson et al. [9], Petrus and Ferguson [10], and Freborg et al. [11]. Rather, we investigate how oxide layers with different thicknesses affect the thermally-induced stress field, with the mean thickness of the bond coat kept fixed. This simulates the introduction of a pre-oxidized layer between the top and bond coats to retard or control the rate of oxygen diffusion into the metallic bond coat, as was done by Koolloos and Houben [12], and allows one to quantify the oxide layer's thickness effect on the stress field.

The analysis of the thermally-induced stresses in the above configurations is conducted using the recently developed version of the higher-order theory for bidirectionally functionally graded materials, referred to as HOTFGM-2D in the literature $[13,14,15,16]$. As described in the next section, this analysis technique offers a comprehensive approach towards modeling the response of material systems with different microstructural details, including certain advantages not available in standard displacement-based finite element techniques. In particular, it is capable of capturing different microstructural details observed in plasma-sprayed coatings, including top coat's porosity and oriented microstructure whose effects remain to be addressed in the literature. The predictive capability of this novel analytical technique demonstrated in this investigation sets the stage for future investigations that will address the effect of these (as well as other) microstructural details on TBC failure mechanisms and durability.

\section{MODELING APPROACH}

HOTFGM-2D is based on a geometric model of a heterogeneous composite having finite dimensions in the $x_{2}-x_{3}$ plane and extending to infinity in the $x_{1}$ direction, Fig. 2. In the $x_{2}-x_{3}$ plane, the composite is functionally graded with an arbitrary distribution of inclusions of arbitrary cross section. The loading applied to the composite may involve an arbitrary temperature or heat flux distribution and mechanical effects represented by a combination of surface displacements and/or tractions in the $x_{2}-x_{3}$ plane, and a uniform strain in the $x_{1}$ direction.

The functionally graded microstructure in the $x_{2}-x_{3}$ plane is modeled by discretizing the heterogeneous composite's cross section into $N_{q}$ and $N_{\tau}$ generic cells in the intervals $0 \leq x_{2} \leq H$, $0 \leq x_{3} \leq L$. The generic cell $(q, r)$ used to construct the composite, highlighted in Fig. 2, consists 
of four subcells designated by the pair $(\beta \gamma)$, where each index $\beta, \gamma$ takes on the values 1 or 2 which indicate the relative position of the given subcell along the $x_{2}$ and $x_{3}$ axis, respectively. The indices $q$ and $r$, whose ranges are $q=1,2, \ldots, N_{q}$ and $r=1,2, \ldots, N_{r}$, identify the generic cell in the $x_{2}-x_{3}$ plane. The dimensions of the generic cell along the $x_{2}$ and $x_{3}$ axes, $h_{1}^{(q)}, h_{2}^{(q)}$, and $l_{1}^{(r)}, l_{2}^{(r)}$, can vary in an arbitrary fashion such that

$$
H=\sum_{q=1}^{N_{q}}\left(h_{1}^{(q)}+h_{2}^{(q)}\right) \quad L=\sum_{r=1}^{N_{r}}\left(l_{1}^{(r)}+l_{2}^{(r)}\right)
$$

Given the applied thermomechanical loading, an approximate solution for the temperature and displacement fields is constructed based on volumetric averaging of the field equations together with the imposition of boundary and continuity conditions in an average sense between the subvolumes used to characterize the material's microstructure. As described briefly in the appendix, this is accomplished by approximating the temperature and inplane displacement fields in each subcell of a generic cell using a quadratic expansion in the local coordinates $\bar{x}_{2}^{(\beta)}, \bar{x}_{3}^{(\gamma)}$ centered at the subcell's centroid. A higher-order representation of the temperature and displacement fields is necessary in order to capture the local effects created by the thermomechanical field gradients, the microstructure of the composite and the finite dimensions in the functionally graded directions. The out-of-plane displacement, on the other hand, is approximated using linear expansion in local coordinates which reflects the material's continuous microstructure in the out-of-plane direction. The unknown coefficients associated with each term in the temperature and displacement field expansions are then obtained by constructing systems of equations that satisfy the requirements of a standard boundary-value problem for the given field variable approximations. That is, the heat and equilibrium equations are satisfied in a volumetric sense, and the thermal and heat flux continuity conditions, and the displacement and traction continuity conditions, within a given cell, as well as between a given cell and its adjacent neighbors, are imposed in an average sense.

Similarities and differences between this approach and standard displacement-based finiteelement formulations have been described elsewhere [17]. An important advantage of the present approach is the simultaneous satisfaction of displacement and traction continuity conditions between the different subvolumes of the spatially variable microstructure. This facilitates the determination of thermally-induced stresses across the top coat/bond coat interface in the present application which cannot be easily captured due to very localized and very steep gradients in the thickness direction as will be demonstrated.

The volume discretization employed in HOTFGM-2D allows one to represent the geometries of different types of spatially variable material architectures in sufficient detail. For instance, this approach was recently employed in modeling thermally-induced stresses in functionally graded TBCs subjected to thermal gradient cyclic loading, illustrating how creep-induced stress redistribution depends on the level of microstructural refinement [17]. In the present application of HOTFGM$2 \mathrm{D}$, we discretize the repeating cross-section element of the TBC system shown in Fig. 1(b) in order to model the geometric details associated with different degrees of interfacial roughness and different oxide layer thickness. The mean top coat and bond coat thickness are the same as those investigated by Freborg et al. [11], using circular specimen geometry, while the substrate thickness is different due to the absence of curvature in our specimen geometry. The results of this volume discretization in the region around the wavy interface are shown in Fig. 3 for the three levels of interfacial roughness, herein called low, standard and high. The wavelength of a single sinusoidal waveform is $50 \mu \mathrm{m}$ and the crest amplitude is fixed at $10 \mu \mathrm{m}$ while the trough amplitude is 4,10 
and $16 \mu \mathrm{m}$ for the low, standard and high interfacial roughness, respectively. The standard interface roughness in our investigation has the same wavelength to amplitude ratio as that employed by Ferguson et al. [9]. Included in Fig. 3 are the dimensions of thin and thick oxide layers for the standard interfacial roughness. As is observed, the chosen volume discretization adequately depicts the different levels of interfacial roughness.

The material thermoelastic and viscoplastic parameters that govern the response of the individual TBC constituents are given in Table 1 [9]. The viscoplastic response of the Zr-based top coat, $\mathrm{NiCI}$-based bond coat, and $\mathrm{Ni}$-based substrate is modeled by a power-law creep equation, generalized to multi-axial loading situations as follows,

$$
\dot{\varepsilon}_{i j}^{c}=\frac{3 F\left(\sigma_{e}, T\right)}{2 \sigma_{e}} \sigma_{i j}^{\prime}
$$

where $\sigma_{i j}^{\prime}$ are the components of the stress deviator, $\sigma_{e}=\sqrt{3 / 2 \sigma_{i j}^{\prime} \sigma_{i j}^{\prime}}$, and

$$
F\left(\sigma_{e}, T\right)=A(T) \sigma_{e}^{n(T)}
$$

where the temperature-dependent parameters $A, n$ are listed in the table in the range $10-1200^{\circ} \mathrm{C}$. These are the same as the parameters used by Freborg et al. [11], as are the temperature-dependent thermal expansion coefficients. However, average values of the Young's moduli over the specified temperature range provided by the above authors were used in our calculations for computational efficiency as discussed below.

Table 1. Thermoelastic and creep material parameters of the TBC constituents (after Ferguson et al. [9]).

\begin{tabular}{lccccc}
\hline \multicolumn{1}{c}{ Material } & $E(\mathrm{GPa})$ & $\nu$ & $\begin{array}{c}\alpha\left(10^{-6} /{ }^{\circ} \mathrm{C}\right) \\
10^{\circ} \rightarrow 1200^{\circ} \mathrm{C}\end{array}$ & $\begin{array}{c}A\left(\mathrm{MPa}^{-n} / \mathrm{s}\right) \\
10^{\circ} \rightarrow 1200^{\circ} \mathrm{C}\end{array}$ & $\begin{array}{c}n \\
10^{\circ} \rightarrow 1200^{\circ} \mathrm{C}\end{array}$ \\
\hline $\mathrm{Zr}$-based TC & 25.4 & 0.33 & $7.6 \rightarrow 12.5$ & $2.01 \times 10^{-30} \rightarrow 1.85 \times 10^{-7}$ & $1.0 \rightarrow 3.0$ \\
$\mathrm{Al}_{3} \mathrm{O}_{2}$ layer & 380 & 0.26 & 8.6 & - & - \\
$\mathrm{NiCr}$-based BC & 156 & 0.27 & $12.0 \rightarrow 14.4$ & $4.39 \times 10^{-40} \rightarrow 7.40 \times 10^{-6}$ & $1.0 \rightarrow 3.0$ \\
Ni-based SUB & 156 & 0.27 & $12.0 \rightarrow 19.3$ & $4.85 \times 10^{-36} \rightarrow 2.25 \times 10^{-9}$ & $1.0 \rightarrow 3.0$ \\
\hline
\end{tabular}

The creep model employed in this investigation requires considerable computational effort to solve the governing systems of equations described in the appendix which characterize the temperature and deformation fields in the individual subcells of the discretized repeating cross section element. This is due to the high creep, and thus relaxation, rates at elevated temperatures that the TBC constituents experience for the given creep parameters and thermal loading. In the present investigation, a forward Euler integration technique was employed to integrate the governing equations using a variable time step. Very small time steps were required during the heatup and cooldown portions of the thermal cycle to obtain convergent solutions. This, in turn, necessitated the use of average Young's modulus values over the considered temperature range in order to avoid the need to invert the large global stiffness matrix in the governing equations at each time increment. Convergent solutions were obtained as verified by repeating the calculations for decreasingly smaller time increments, as well as by ensuring that the continuity of interfacial tractions across the top coat/bond coat interface was satisfied. 
Finally, the spatially-uniform thermal loading applied to the TBC system is shown in Fig. 4. It consists of a heatup, hold, and cooldown portions over a period of $630 \mathrm{sec}$. Again, this is the same loading cycle as that employed by Freborg et al [11]. Three thermal cycles were sufficient to delineate the major response characteristics for the considered material combinations, geometry and temperature range due to the rapid stress relaxation within the TBC constituents during the hold period. We note that transient effects were not taken into account in performing the calculations (i.e., steady-state thermomechanical analysis was employed) due to the relatively slow rate of heating/cooling employed in the thermal loading history (which, as previously mentioned, simulates furnace heating). Transient effects would certainly become important when simulating thermal shock tests, and can easily be accommodated by the higher-order theory. In addition, residual stresses were not included in the calculations due to the complete stress relaxation that occurs during the hold portion of the thermal cycle for the employed thermal history, as will be seen in the next section. It must be mentioned, however, that for other thermal histories for which complete stress relaxation does not occur in the individual constituents (in the presence of a through-thickness temperature gradient, for example), fabrication-induced residual stresses may play a role. Further, residual stresses due to fabrication may induce initial damage which may accelerate the spallation mechanism. It has been reported, for instance, that spallation occurs sooner when a coating is plasma-sprayed onto an excessively hot substrate [18].

\section{RESULTS}

The results presented herein emphasize the influence of interfacial roughness and fixed oxide layer thickness on the through-thickness $\left(\sigma_{33}\right)$ stress that is thought to be responsible for the formation of horizontal cracks in plasma-sprayed coatings in the vicinity of the top coat/bond coat interface's crest. However, the transverse $\left(\sigma_{22}\right)$ stress is also included in the section addressing the oxide layer thickness effect as large magnitudes of this stress arise in the oxide layer itself and may potentially lead to the oxide film's degradation. These stresses are presented at critical locations as a function of time, as well as through critical cross sections (both vertical and horizontal) at those points in time that correspond to the maximum magnitudes of these stress components.

The presentation of the results is divided into two parts. In the first part, we initially demonstrate the convergence of our solution technique by focusing on the interfacial traction continuity across the top coat/bond coat interface, and then investigate the influence of interfacial roughness on the through-thickness stress in the absence of an oxide layer. In the second part, we investigate the effect of varying the oxide layer thickness on both stress components for the standard interfacial roughness, and compare the results with those when the oxide layer is absent.

\subsection{Interface Roughness Effects}

Figure 5 illustrates the evolution of the through-thickness stress across the crest and trough of the top coat/bond coat interface during the first thermal cycle for a low and a high interface roughness in the absence of an oxide layer. The stresses in the center of two adjacent subcells lying on the top coat and bond coat side of the interface's crest and trough are displayed in order to demonstrate the interfacial traction continuity satisfied by the higher-order theory formulation. As mentioned in the foregoing, the satisfaction of the interfacial traction continuity in the presence of very rapid relaxation of the stress field at elevated temperatures requires careful integration of the governing systems of equations presented in the appendix. The demonstrated traction 
continuity gives us confidence in the results that will be discussed in the sequel. To achieve a comparable level of traction continuity satisfaction using the displacement-based finite-element approach requires substantial mesh refinement in the interfacial region where the stress gradients become very pronounced during heatup and cooldown. The level of traction continuity satisfaction observed in our results may be difficult to achieve using the displacement-based finite-element analysis as suggested by the initial results reported by Ferguson et al. [9].

The stress profiles in Fig. 5 indicate that the maximum magnitudes of the through-thickness stress occur during the initial heatup portion of the thermal cycle (at about $30 \mathrm{sec}$ ) and after cooldown (at $630 \mathrm{sec}$ ). During the initial heatup period, the through-thickness stress becomes compressive across the interface's crest and tensile across the interface's trough. After the stresses at these locations reach their maximum values at $30 \mathrm{sec}$ or $825^{\circ} \mathrm{C}$, they quickly decay to zero before the initial heatup is completed due to the rapid stress relaxation at the elevated temperature. Therefore, during the cooldown portion of the thermal cycle, the through-thickness stress becomes tensile across the interface's crest and compressive across the interface's trough, with the maximum magnitudes occurring upon the cycle's completion at 630 sec. During subsequent thermal cycles (not shown), the through-thickness stress across the interfacial crest and trough initially decreases to zero during the heatup portion and subsequently retraces its path during cooldown, attaining the same maximum values as those after the first cycle. Thus the trough, in the absence of an oxide layer, will be subjected to either zero or compressive through-thickness stress during subsequent thermal cycling for the chosen TBC material system and thermal loading profile, eliminating the possibility of horizontal crack growth in this region. This will be true whether or not the interface at the trough survives the initial heatup. Alternatively, the crest will be subjected to tensile throughthickness stress during subsequent thermal cycles upon cooldown, which provides the driving force for horizontal crack growth initiated by local delamination.

The results of Fig. 5 indicate that varying the interfacial roughness by keeping the interfacial crest amplitude fixed while changing the interfacial trough amplitude has a substantial influence on the through-thickness stress across the trough, with the stress across the crest affected to a very small extent. This localized effect is more fully illustrated in Fig. 6 which shows the throughthickness stress evolution across the interface's crest and trough for the three levels of interfacial roughness. At the crest location, the maximum through-thickness stress upon completion of the first and subsequent cycles occurs at the bond coat/top coat interface for all interface roughnesses. For the standard interface roughness it is $65 \mathrm{MPa}$. Decreasing the interface roughness reduces the maximum stress to $59 \mathrm{MPa}$, and increasing the interface roughness increases the maximum stress to $69 \mathrm{MPa}$. At the trough location, the maximum through-thickness stress occurs at the bond coat/top coat interface only for the high interface roughness as seen in Fig. 7 (see Fig. 3(a) for interface locations), which shows the stress distributions along the vertical cross section passing through the interface's trough at the end of the first and subsequent cycles. The maximum throughthickness stress for the high interface roughness is $-153 \mathrm{MPa}$. For the standard interface roughness the maximum stress is $-99 \mathrm{MPa}$ and occurs in the bond coat $3 \mu \mathrm{m}$ below the bond coat/top coat interface, decreasing to $-80 \mathrm{MPa}$ at the interface. The maximum through-thickness stress for the low interface roughness, $-55 \mathrm{MPa}$, also occurs in the bond coat, $3 \mu \mathrm{m}$ below the bond coat/top coat interface, decreasing to $-47 \mathrm{MPa}$ directly at the interface.

The through-thickness stress magnitudes at the crest and trough of the bond coat/top coat interface of the standard interface roughness generated by our analysis are comparable to the results obtained by Freborg et al. [11]. These authors have obtained 75 and $-50 \mathrm{MPa}$ at the crest and trough locations upon cooldown, respectively, versus 65 and $-80 \mathrm{MPa}$ obtained by our analysis. 
The observed differences are likely due to the difference in the interfacial roughness representation (i.e., single vs double sine waveforms) and specimen geometry (curved vs flat geometry).

It is important to note that if the manner of varying the interface roughness were reversed by keeping the trough amplitude fixed while changing the crest amplitude, a smilar effect will also be observed. That is, the interfacial through-thickness stress at the trough would be affected very little, with the stress at the crest affected to a similar extent as at the trough in the present situation.

We end this section by presenting the horizontal (along the $x_{2}$ direction) through-thickness stress distributions at the elevation passing through the crest of the bond coat/top coat interface $\left(x_{3}=640\right.$ $\mu m$, see Fig. 3(a)) in Fig. 8 to demonstrate how they are affected by the interface roughness, and to provide comparison with the results of the following section. As observed (and suggested by the vertical distributions in Fig. 7), the tensile through-thickness stress at the crest location changes to compression in the top coat region above the trough. The low interface roughness decreases the magnitude of the compressive stress somewhat while the high interface roughness increases it relative to the stress distribution for the standard interface roughness. Corresponding distributions will be presented in the following section to demonstrate how the through-thickness stress to either side of the crest is dramatically affected by the introduction of an oxide layer.

\subsection{Oxide Layer Thickness Effects}

Next, we demonstrate the effect of oxide layer thickness on the through-thickness stress for the standard interface roughness, and then focus on the transverse stress. Figure 9 compares the through-thickness stress evolution with time at points just below the crest and trough locations (on the bond coat side of the bond coat/top coat and bond coat/oxide layer interface) of the interfaces without and with an oxide layer. At this particular location, the presence of the oxide layer increases the magnitude of the through-thickness stress during the intial heatup and subsequent cooldown to a substantially greater degree than the corresponding increase due to the interfacial roughness. As before, during subsequent cycles, the residual stresses decrease to zero during the heatup period, remain zero during the hold period, and retrace the same path during cooldown as in the first cycle.

More insight into the oxide layer-induced stress amplification is obtained by considering the through-thickness stress distributions in the vertical cross sections passing through the crest and trough at the end of each cycle. These are presented in Fig. 10. In the cross section passing through the crest, the maximum stress (65 MPa) in the absence of the oxide layer occurs exactly at the bond coat/top coat interface $\left(x_{3}=640 \mu \mathrm{m}\right)$ as discussed previously. The introduction of a thin oxide layer increases the maximum stress to 169 MPA and moves its location $1 \mu \mathrm{m}$ below the bond coat/oxide layer interface. At the bond coat/oxide layer and oxide layer/top coat interface the through-thickness stress rapidly decreases to 71 and $42 \mathrm{MPa}$, respectively, increasing again to $52 \mathrm{MPa} 2 \mu \mathrm{m}$ above the oxide layer/top coat interface $\left(x_{3}=643 \mu \mathrm{m}\right)$, and subsequently decaying to zero in a manner similar to that when the oxide layer is absent. In the presence of the thick oxide layer the maximum stress further increases to $500 \mathrm{MPa}$ and its location moves back up to the bond coat/oxide layer interface. The through-thickness stress rapidly decreases within the oxide layer with increasing distance from the bond coat/oxide layer interface, changing from tension to compression within the oxide layer itself in contrast to the thin layer case. It attains its greatest compressive value of $52 \mathrm{MPa}$ at the oxide layer/top coat interface $\left(x_{3}=643 \mu \mathrm{m}\right)$ at which point it reverses direction, becoming tensile a small distance from this interface ( $21 \mathrm{MPa}$ at $x_{3}=650 \mu \mathrm{m}$ ), reversing direction again and finally decaying to zero. 
Similar qualitative behavior is observed in the cross section passing through the trough, except for the sign of the through-thickness stress. In this case, the location of the maximum magnitude of the compressive through-thickness stress relative to the bond coat interface is slightly different in each case. In the absence of the oxide layer, the compressive through-thickness stress attains its greatest magnitude at an elevation $3 \mu \mathrm{m}$ below the bond coat/top coat interface, as discussed previously. The introduction of a thin oxide layer moves the maximum stress location to the bond coat/oxide layer interface. This is further moved up into the oxide layer itself $1 \mu \mathrm{m}$ above the bond coat/oxide layer interface when the oxide layer thickness is increased. The decay of the throughthickness stress with increasing distance from the location where its magnitude is maximum is monotonic when the layer is thin, and has the same character as in the cross section passing through the crest (except for the sign). In the case of the thick oxide layer, however, the throughthickness stress reverses sign, becoming tensile outside the oxide layer, and attains a maximum value of $16 \mathrm{MPa}$ at the elevation of $630 \mu \mathrm{m}$ (average bond coat/top coat interface) above which it decreases to zero. This is similar to the sign reversal in the through-thickness stress observed in the cross section passing through the crest for the thick oxide layer case, except now the sign reversal occurs in the top coat above the oxide layer/top coat interface.

The substantial stress amplification due to the oxide layer suggests that the initiation of delamination at the crest upon cooldown may potentially occur at the bond coat/oxide layer interface for both oxide layer thicknesses if the interfacial bond is weak (in the case of the thin oxide layer, the delamination initiation in the bond coat just below the bond coat/oxide layer interface where the maximum stress occurs can probably be ruled out for a dense Ni-based alloy). Subsequent delamination growth along this crest elevation in the horizontal cross section depends on several factors, including the strength of the bond coat/oxide layer interface, the bond coat/oxide layer Young's modulus mismatch, and the stress distribution in the oxide layer itself. Consideration of these factors leads one to the conclusion that delamination growth at this elevation into the oxide layer does not appear to be favorable. First, a weak bond coat/oxide layer interface would tend to deflect the delamination along the interface towards the trough region (where a compressive state of stress exists). This crack deflection is also driven by the lower value of the bond coat's Young's modulus relative to that of the oxide layer (for a high density oxide film). Further, the state of through-thickness stress in the horizontal cross sections through the considered crest elevation is not favorable to delamination growth. The through-thickness stress distributions are presented in Fig. 11 at several elevations through the crest.

In the case of the thin oxide layer, the horizontal stress distributions are given at three elevations, namely: $0.5 \mu \mathrm{m}$ below and above the bond coat/oxide layer interface; and $1.0 \mu \mathrm{m}$ above the oxide layer/top coat interface, or at $x_{3}=639.5,640.5$ and $642.0 \mu \mathrm{m}$ (see Fig. 3(b)). As is observed, the initially tensile through-thickness stress directly below the bond coat crest (at $x_{3}=639.5 \mu \mathrm{m}$ ) becomes compressive immediately to either side of the crest within the oxide layer, and exhibits an oscillatory behavior with increasing $x_{2}$ coordinate, going into small tension, and relatively greater compression. In the top coat region the through-thickness stress increases to a maximum value of $63 \mathrm{MPA}$ at $x_{2}=20 \mu \mathrm{m}$ before it converges to the distribution observed previously in the absence of the oxide layer. The compressive region around the bond coat crest would thus tend to retard delamination growth at this elevation. At the higher elevation, $x_{3}=640.5 \mu \mathrm{m}$, the magnitude of the tensile stress directly above the bond coat crest decreases relative to the lower elevation while the extent of compression to either side of the crest increases. However, the extent of the compressive region is smaller due to only one oscillation. A relatively high tensile stress ( $148 \mathrm{MPa}$ ) occurs a small horizontal distance from the crest at $x_{2}=18 \mu \mathrm{m}$, which in fact is greater than the 
stress directly below the bond coat crest at the lower elevation. However, it occurs within the oxide layer at the oxide layer/top coat interface and drops down to $61 \mathrm{MPa}$ on the top coat side of the interface. This stress decays with increasing $x_{2}$ coordinate, converging to the previous distribution around $x_{2}=25 \mu \mathrm{m}$. The above suggests the possibility of delamination initiation in the top coat region to either side of the bond coat crest, with subsequent growth away from the crest arrested by the compressive zone above the trough region. At the highest elevation, $x_{3}=642.0 \mu \mathrm{m}$, which is purely in the top coat region, the magnitude of the tensile through-thickness stress directly over the crest is further decreased slightly and the decrease of the stress with increasing $x_{2}$ coordinate is substantially more gradual than at the lower elevations. In fact, the through-thickness stress never becomes compressive, reaching a minimum, then increasing somewhat and finally decaying to the distribution observed in the absence of the oxide layer. The above results indicate that the introduction of a thin oxide layer reduces the maximum tensile through-thickness stresses in the top coat in the vicinity of the crest where delamination initiation and growth are likely to occur relative to those when the oxide layer is absent. These results also suggest that delamination growth may involve coalescence of two delaminations initiated directly over, and to either side and below, the crest of the oxide layer/top coat interface.

In the case of the thick oxide layer, horizontal through-thickness stress distributions are given at four elevations, with the first three located at the same elevations as in the thin oxide layer case and the remaining $1 \mu \mathrm{m}$ above the oxide layer/top coat interface, or at $x_{3}=639.5,640.5,642.0$ and $644.0 \mu \mathrm{m}$ (see Fig. 3(b)). The trends in the horizontal through-thickness stress distributions are similar to those observed in the case of the thin oxide layer, with a few notable exceptions. The large tensile through-thickness stress directly at the crest of the bond coat/oxide layer interface decreases with increasing elevation until it becomes compressive within, at and just above the oxide layer/top coat interface (as already seen in Fig. 10), in contrast with the preceding case where only tensile stress was seen. The magnitudes of the compressive through-thickness stress in the oxide layer immediately to either side of the crest are substantially greater relative to the thin oxide layer case, and they extend further to either side of the crest due to the greater thickness of the layer. The off-peak stress oscillations are also relatively smaller, with the tensile off-peak values smaller than the values directly at or above the crest (with the exception of the highest elevation). The largest off-peak tensile through-thickness stress $(89 \mathrm{MPa})$ in the top coat occurs at the elevation $x_{3}=640.5 \mu \mathrm{m}$ and the horizontal distance $x_{2}=22 \mu \mathrm{m}$, which is greater than the corresponding stress in the top coat in the thin oxide layer case at the same vertical elevation but at $x_{2}=18 \mu \mathrm{m}$. The above observations suggest that, as in the preceding case, the potential for the initiation of delamination directly at the crest of the bond coat/oxide layer interface caused by the high tensile stress induced by the oxide layer is mitigated by the clamping action of the compressive stress to either side of the oxide layer. Further, the maximum tensile stress that occurs in the top coat above the oxide layer/top coat interface (at $x_{3}=650 \mu \mathrm{m}$, see Fig. 10) is significantly reduced. This effectively moves the delamination initiation site to the off-peak location in the top coat region slightly above the crest of the bond coat/oxide layer interface.

The increase in the oxide layer thickness also decreases the magnitude of the compressive through-thickness stress in the top coat region over the trough at horizontal elevations passing through the crest. This is more clearly shown in Fig. 12 where through-thickness stress distributions at the same elevation $x_{3}=640.5 \mu \mathrm{m}$ are given in the interval $20 \leq x_{2} \leq 50 \mu \mathrm{m}$ for the standard interfaces without and with thin and thick oxide layers. Increasing the oxide layer thickness is thus expected to facilitate delamination growth through the top coat region above the trough. 
The last set of results demonstrates the effect of the oxide layer thickness on the transverse stress component $\sigma_{22}$ in the plane of the layered TBC system. This stress component arises due to the thermomechanical property mismatch between the individual regions regardless of the presence or absence of the rough interface and may potentially lead to the formation of vertical cracks. The magnitude of the transverse stress also depends on the geometry of the TBC system, and in particular on the substrate thickness. In the absence of a rough interface, the through-thickness (along the $x_{3}$ coordinate) distribution of the transverse stress exhibits abrupt jumps or discontinuities across the boundaries separating the substrate, the bond coat and the top coat because of the aforementioned thermomechanical property mismatch and also because this stress is not a traction component along this direction. In the absence of an oxide layer, the rough interface smooths out these abrupt jumps while the introduction of an oxide layer gives rise to large localized transverse stress discontinuities within, and in the immediate vicinity of, the oxide layer itself due to the layer's large Young's modulus. During the heating portion of the thermal cycle, the transverse stress component is initially negative in the substrate and positive in both the bond and the top coat such that the through-thickness integral of this stress component is zero due to the generalized plane strain boundary conditions imposed on the TBC system in its plane. Due to the high relaxation rates, the transverse stress decreases to zero at the elevated temperature and at the end of the thermal cycle becomes positive in the substrate and negative in the bond coat and the top coat. During subsequent thermal cycles, the transverse stress decreases to zero in the three regions during the heatup portion and retraces its path during the cooldown portion as observed previously with the through-thickness stress.

Figures 13 and 14 demonstrate the effect of the oxide layer thickness on the transverse stress distributions along the vertical cross sections (along the $x_{3}$ coordinate) passing through the standard interface's crest and trough during the initial heatup portion of the cycle at $30 \mathrm{sec}$ and after cooldown at 630,1260 and $1890 \mathrm{sec}$ (end of first, second and third cycles). In the absence of an oxide layer, the transverse stress smoothly decreases as the rough interface's crest is traversed from the bond coat into the top coat, becoming less tensile and less compressive in the top coat region away from the crest at $30 \mathrm{sec}$ and after cooldown, respectively, Figs. 13(a) and 14(a). An initial increase in the magnitude of the transverse stress is observed as the bond coat/top coat interface is approached through the rough interface's trough, followed by an initially rapid and then a more gradual decrease, Figs. 13(b) and 14(b). The presence of the oxide layer has a very localized effect on the transverse stress in both cross sections. During the initial heatup, Fig. 13, large tensile stress occurs within the oxide layer which increases with increasing oxide layer thickness. The region just outside the oxide layer is also affected in a manner that depends on the oxide layer thickness and the vertical cross section. In the case of the thin oxide layer at the crest location, Fig. 13(a), the region just below the bond coat/oxide layer interface sees a substantially higher transverse stress relative to the stress in this region in the absence of an oxide layer. The opposite is seen in the case of the thick oxide layer whose presence now lowers the transverse stress in the regions just outside the layer itself. At the trough location, Fig. 13(b), on the other, the initial increase in the transverse stress at the bond coat/top coat interface in the absence of the oxide layer is suppressed by the introduction of a thin oxide layer, while the transverse stress in the top coat at the oxide layer/top coat interface is enhanced. As the oxide layer thickness is increased, the transverse stress just below the bond coat/oxide layer interface is furthered lowered, with no additional increase above the oxide layer/top coat interface. The presence of the oxide layer has a greater effect in the trough where larger tensile transverse stresses are observed within the oxide layer relative to the oxide layer at the crest. It should be noted that the maximum values of the transverse stress 
during the heatup portion of the thermal cycle do not occur at the same time as was the case with the through-thickness stress component. The critical times fall within the time interval between 30 and $50 \mathrm{sec}$ and depend on the location and the oxide layer thickness. The distributions presented at $30 \mathrm{sec}$, however, do provide a good representation of the effect of the oxide layer's thickness on the magnitude of the transverse stress. Similar trends are observed at the end of the first as well as subsequent cycles, Fig. 14, except now the sign of the transverse stress is reversed. Further, the magnitudes of the compressive transverse stress in the oxide layer at the crest and trough are larger than the magnitudes of the tensile transverse stress at the corresponding locations during the initial heatup.

The above results indicate that the magnitudes of the transverse stress within the oxide layer are substantially greater than the magnitudes of the through-thickness stress for the present TBC geometry. Should a vertical crack develop through the oxide layer during the initial heatup due to the large transverse tensile stress at the crest and trough locations, this crack may propagate into the top and bond coats due to the favorable Young's modulus mismatch. Further, failure in compression at sufficiently large magnitudes of the transverse stress must not be ruled out as well. These observations point to the desirability of maintaining the oxide layer thickness below a certain level in order to eliminate the possibility of either a vertical crack formation or a compressive failure mode due to excessively large tensile or compressive transverse stress. The desirability of optimizing the oxide layer thickness is further supported by the examination of the remaining two stress components not discussed thus far. The out-of-plane normal stress $\left(\sigma_{11}\right)$ also becomes progressively larger with increasing oxide layer thickness during the initial heatup, and may produce cracks within the oxide layer transverse to the $x_{1}$ axis. In fact, this stress component during the initial heatup is larger than the transverse stress. Its magnitude after cooldown, however, is relatively small. The inplane shear stress $\left(\sigma_{23}\right)$ also increases rapidly with increasing oxide layer thickness and attains maximum values at locations to either side of the crest. Its effect on potential delamination during cooldown is not clear, however, due to the clamping action of the throughthickness stress normal stress at these locations.

\section{SUMMARY AND DISCUSSION OF RESULTS}

As demonstrated by Koolloos and Houben [12], pre-oxidizing the bond coat to a thickness of 2 $\mu m$ enhanced the durability of a PSZ TBC system during furnace tests. The oxide layer consisted predominantly of $\alpha-\mathrm{Al}_{2} \mathrm{O}_{3}$. Failures occurred by spallation of the top coat upon cooldown. The results of our analysis shed light on the effect of the oxide layer thickness on the through-thickness (and also transverse) stress at the critical crest and trough locations of a rough top coat/bond coat interface. Such analysis can aid in optimizing the initial oxide film thickness for a specific TBC architecture and material system.

Increasing the oxide layer thickness leads to dramatic increases in the magnitudes of the throughthickness stress at the bond coat/oxide layer interface and also within the oxide layer itself at the crest and trough locations after cooldown. The interfacial stress becomes more tensile and more compressive at the crest and trough locations, respectively. The increase in the tensile throughthickness stress, however, is offset by the compressive stress that develops immediately to either side of the crest, thereby providing a clamping action that should prevent delamination cracks from propagating across the oxide layer and into the top coat. The magnitude of this compressive stress increases with increasing oxide layer thickness. For a given oxide layer thickness, the throughthickness stress within the oxide layer at the crest decreases with increasing vertical distance from 
the bond coat/oxide layer interface in the direction of the top coat, becoming less tensile at the oxide layer/top coat interface in the case of the thin oxide layer and compressive in the case of the thick oxide layer. This is accompanied by smaller magnitudes of the compressive stress in the locations immediately to either side of the crest at fixed elevations. Above the crest of the oxide layer/top coat interface, a small increase in the stress relative to that at the interface is observed in the case of the thin oxide layer. In the case of the thick oxide layer, a sign reversal occurs and the through-thickness stress becomes tensile again. Its magnitude, however, is substantially smaller than in the thin oxide layer case.

The above results suggest that the thickness of the oxide layer has an influence on the manner in which delamination growth in the top coat will proceed, as is typically observed in plasma-sprayed TBCs. In the absence of the oxide layer, the maximum through-thickness stress (65 MPa) upon cooldown occurs at the crest of the bond coat/top coat interface and so the delamination is likely to initiate and proceed along this elevation. Its growth, however, should be somewhat mitigated by the change in the sign of the through-thickness stress with increasing horizontal distance from the crest. The introduction of a thin oxide layer moves the maximum stress ( $52 \mathrm{MPa}$ ) in the top coat at the crest location $2 \mu \mathrm{m}$ above the oxide layer/top coat interface, making it likely that delamination initiation and growth will proceed through this point and not through the crest of the oxide layer/top coat interface where the stress is $42 \mathrm{MPa}$ (provided that the interface is sufficiently strong). Since the thin oxide layer reduces the maximum through-thickness stress in the top coat at the crest location relative to a TBC without an oxide layer, delamination initiation at this location should require a greater number of thermal cycles. However, the thin oxide layer also increases the through-thickness stress to $61 \mathrm{MPa}$ in the top coat to either side of the crest at an elevation below the oxide layer/top coat interface, potentially creating another delamination initiation site. The delamination growth at this and higher elevation should be mitigated by the compressive throughthickness stress away from the crest (in the top coat region above the trough) which has the same distribution as that in the absence of the oxide layer.

The introduction of a thick oxide layer decreases the maximum through-thickness stress in the top coat at the crest location to $21 \mathrm{MPa}$ which occurs $7 \mu \mathrm{m}$ above the oxide layer/top coat interface, further decreasing delamination initiation susceptibility at this elevation. However, this is offset by an increase in the through-thickness stress in the top coat to either side of the crest at the lower elevations, thereby potentially moving the delamination initiation site from the location directly above the crest to a location in the top coat to either side of the crest. Further, increasing the oxide layer thickness facilitates delamination growth between the rough interface's crests by reducing the compressive through-thickness stress in the top coat above the trough region.

The above discussion indicates that the oxide layer thickness should be optimized in a way that decreases the delamination initiation susceptibility in the top coat directly above, or immediately to either side of, the crest, while reducing the delamination growth potential between adjacent crests. Such optimization must take into account subsequent oxide film growth during exposure to elevated temperature. Another reason for optimizing the oxide layer thickness are the large throughthickness and transverse stresses that develop in the oxide layer during thermal cycling. These large stresses can lead to the degradation of the oxide layer itself, thereby producing additional failure initiation sites. The magnitude of transverse stress also depends on the TBC geometry, and in particular the substrate thickness which also must be taken into account in choosing on optimal oxide film thickness. 
The results of our study can also be compared and contrasted with those presented by Freborg et al. [11]. These authors have modeled the oxidation of the bond coat layer, allowing the bond coat thickness to continuously decrease with exposure to elevated temperature with increasing oxide layer thickness, while in the present study the bond coat thickness and the oxide layer are fixed. However, the thickness of the oxide layer relative to the rough interface's amplitude was relatively small. Further, the effect of the oxide layer growth on the resulting stress field should be small due to the high relaxation rates within the TBC constituents at the elevated temperature at which oxide growth was modeled. Any significant differences in the stress distributions between the two studies should thus be attributable to the model specimen geometry (cylindrical specimen vs flat plate), the waveform used to model the rough interface (single sine wave vs double sine wave), and the method of solution (f-e vs HOTFGM). The accuracy of the higher-order theory was demonstrated in previous investigations [16]. In the study of Freborg et al. [11], stress distributions are presented for a TBC without an oxide layer, and for a TBC with a growing oxide layer, at the end of 4 and 51 thermal cycles. The thickness of the oxide layer after 4 and 51 cycles was approximately 0.3 and $1.0 \mu \mathrm{m}$, respectively, which are somewhat smaller relative to the waveform amplitude than our thin and thick oxide layers, respectively.

First, both studies indicate comparable magnitudes and distributions of the through-thickness stress in the top coat region at the crest location in the absence of the oxide layer. Also, both studies indicate that the through-thickness stress after cooldown at the crest of the oxide layer/top coat interface decreases with increasing oxide layer thickness, and becomes compressive when the oxide layer becomes sufficiently large. However, the magnitude of the compressive stress after 51 thermal cycles in the study by Freborg et al. [11] is substantially smaller than the magnitude of the compressive stress in our study for the thick oxide layer, which is likely attributable to the smaller oxide layer thickness relative to the waveform amplitude. Further, while Freborg et al. [11] predict that the stress at the trough of the oxide layer/top coat interface changes from compression to tension after 4 cycles with an additional, but relatively smaller, increase after 51 cycles, our results indicate that the stress becomes less compressive (but not tensile) with increasing oxide layer thickness at this interface. This cannot be explained by the smaller relative oxide layer thickness in the Freborg et al. [11] study, and is most likely due to the differences in the waveforms and specimen curvature employed in the two studies. However, stress reversal in the trough region from compression to tension (smaller than in the Freborg et al. [11] study) is predicted to occur by our model in the top coat at a small distance away from the oxide layer/top coat interface in the case of the thick oxide layer (but not thin). This stress reversal also leads to lowering of the compressive through-thickness stress above the trough at the elevations passing through the crest, while in the study by Freeborg et al. [11], tensile stress was obtained at these elevations after 51 (but not 4) cycles.

Despite these quantitative differences, which are most likely caused by the differences in the relative oxide layer thickness, the waveforms used to model rough interfaces, and the specimen geometry, the qualitative trends predicted by the two models are similar. Our results thus also provide independent support to the hypothesis proposed by Freborg et al. [11] regarding the initiation and subsequent growth of delaminations during bond coat oxidation in plasma-sprayed TBCs with rough interfaces. In this hypothesis, the delamination initiation occurs at the crest of the bond coat/top coat interface (or at the off-peak location) and its growth between adjacent crests is facilitated by the growth of the oxide layer which changes the state of through-thickness stress from compression over the trough to tension. The results of our analysis suggest that the change of the through-thickness stress over the trough regions depends on the specimen geometry 
and perhaps more importantly on the character of the rough interface.

Finally, recent work by Brindley et al. [19] indicates that tailoring the thermal expansion coefficient of the bond coat in the region adjacent to the rough interface can double the TBC's durability. This tailoring was accomplished through a fine dispersion of submicron alumina particles in the bond coat region adjacent to the interface. The higher-order theory employed in the present investigation is ideally suited to modeling and optimizing such advanced TBC systems through the already described subvolume discretization. Future work will address optimal grading of the rough bond coat/top coat interface using the concept proposed by Brindley et al. [19].

\section{CONCLUSIONS}

The pronounced stress relaxation within the TBC constituents due to exposure to elevated temperature during uniform heatup-hold-cooldown thermal cycling changes the state of throughthickness stress at the crest and trough locations of rough bond coat/top coat interfaces in plasmasprayed TBCs. At the crest, the initially compressive through-thickness stress during the heatup portion of the first thermal cycle relaxes to zero at the elevated temperature, thus becoming tensile upon cooldown. The opposite occurs at the trough. During subsequent cycles, the throughthickness stress at both locations decreases to zero during the heatup phase, and returns to the same state upon cooldown as after the first cycle. This sets up the crest location as the initiation site for delamination.

Local variations in the details of the bond coat/top coat interface roughness tend to have a localized effect on the through-thickness stress. Increasing (decreasing) the trough amplitude of a rough interface relative to the crest amplitude increases (decreases) the magnitude of the through-thickness stress at this location, with substantially smaller changes at the crest location. These localized stress perturbations may be substantial, depending on the relative change of the trough (crest) amplitude with respect to the crest (trough) amplitude. The introduction of an aluminum oxide layer between the top and bond coats has a much more significant influence on the through-thickness stress at the crest and trough of the bond coat/oxide layer interface, producing substantially greater amplification in the magnitudes of the through-thickness stress after cooldown which increase with increasing oxide layer thickness. The delamination susceptibility at the crest of the bond coat/oxide layer interface, however, is mitigated by a high compressive stress in the oxide layer to either side of the crest, thereby preventing delamination growth into the oxide layer and the top coat. Further, the oxide layer's effect on the through-thickness stress at the crest of the oxide layer/top coat interface is beneficial, lowering the through-thickness stress at this location with increasing layer thickness even to the point of putting this interface in compression (but not the region above it). Unfortunately, the tensile through-thickness stress in the top coat to either side of, and just below, the crest also increase with increasing oxide layer thickness while the magnitude of the compressive through-thickness stress in the top coat region above the trough of the oxide layer/top coat interface decreases, facilitating delamination initiation and growth at lower elevations. These opposing trends suggest that the oxide layer thickness should be optimized. This is further supported by the high magnitudes of the through-thickness and transverse stresses that develop in the oxide layer itself with increasing layer thickness. The oxide layer thickness optimization must therefore take into account the strength of the alumina layer (which depends on the deposition process), including interfacial strength, and subsequent growth.

The major features of the residual stress evolution in TBCs with rough top coat/bond coat interfaces with an oxide film generated herein using the higher-order theory for functionally graded 
materials are consistent with the results of finite-element analyses reported in the literature. In particular, the results of our investigation support a recently proposed hypothesis regarding delamination initiation and propagation in plasma-sprayed TBCs with evolving bond coat oxidation, while pointing to the importance of interfacial roughness details and specimen geometry in modeling this phenomenon.

\section{Acknowledgements}

The first two authors gratefully acknowledge the support provided by the NASA-Glenn Research Center through the grant NASA NAG 3-1377. The authors also thank Dr. Freborg for his comments on the original version of this report.

\section{REFERENCES}

1. Strangman, T. E. (1985), Thermal Barrier Coatings for Turbine Airfoils, Thin Solid Films, 127, 93-105.

2. Evans, A. G., Crumley, G. B., and Demaray, R. R. (1983), On the Mechanical Behavior of Brittle Coatings and Layers, Oxidation of Metals, 20(5/6), 193-216.

3. NASA CP 3312, Proceedings of the Thermal Barrier Coating Workshop (1995), W. J. Brindley, S. J. Dapkunas \& J. G. Goedjen (Eds). NASA-Lewis Research Center, Cleveland, OH.

4. Miller, R. A. and Lowell, C. E. (1982), Failure Mechanisms of Thermal Barrier Coatings Exposed to Elevated Temperatures, Thin Solid Films, 95, 265-273.

5. Chang, G.C., Phucharoen, W., and Miller, R. A. (1985), Thermal Expansion Mismatch and Oxidation in Thermal Barrier Coatings, Turbine Engine Hot Section Technology 1985, NASA CP 2405, 405-425.

6. Chang, G.C., Phucharoen, W., and Miller, R. A. (1986), A Study on Thermal Barrier Coatings Including Thermal Expansion Mismatch and Bond Coat Oxidation, Turbine Engine Hot Section Technology 1986, NASA CP 2444, 415-434.

7. Chang, G.C., Phucharoen, W., and Miller, R. A. (1987), Behavior of Thermal Barrier Coatings for Advanced Gas Turbine Blades, Surface and Coatings Technology, 30, 13-28.

8. Chang, G.C., Phucharoen, W., and Miller, R. A. (1987), Thermal Expansion Mismatch and Plasticity in Thermal barrier Coatings, Turbine Engine Hot Section Technology 1987, NASA CP 2493, 357-368.

9. Ferguson, B. L., Petrus, G. J., and Ordillas, M. (1994), A Software Tool to Design Thermal Barrier Coatings, NASA Contractor Report No. NAS3-27281, NASA-Lewis Research Center, Cleveland, OH. August 1994.

10. Petrus, G. J. and Ferguson, B. L. (1997), A Software Tool to Design Thermal Barrier Coatings: A Technical Note, J. Thermal Spray Technology, 6(1), 29-34. 
11. Freborg, A. M., Ferguson, B. L., Brindley, W. J., and Petrus, G. J. (1998), Modeling Oxidation Induced Stresses in Thermal Barrier Coatings, Materials Science \& Engineering, A245, 182190.

12. Koolloos, M. F. and Houben, J. M. (1998), Failure Mechanisms During Thermal Cycling and the Effect of a Pre-Oxidized NiCrAlY Bond Coat, in Proceedings of ASM International Materials Solutions 98, Rosemont, Illinois, 12-15, October, 1998.

13. Aboudi, J., Pindera, M-J., and Arnold, S. M. (1996), Thermoelastic Theory for the Response of Materials Functionally Graded in Two Directions, Int. J. Solids 6 Structures, 33(7), 931-966.

14. Aboudi, J., Pindera, M-J., and Arnold, S. M. (1996), Thermoplasticity Theory for Bidirectionally Functionally Graded Materials, J. Thermal Stresses, 19, 809-861.

15. Pindera, M-J., Aboudi, J., and Arnold, S. M. (1998), Higher-Order Theory for the Analysis of Functionally Graded Materials, in Advanced Multilayered and Fiber-Reinforced Composites, Y. M. Haddad (Ed.), pp. 111-132, Kluwer Academic Publishers, The Netherlands.

16. Aboudi, J., Pindera, M-J., and Arnold, S. M. (1999), Higher-Order Theory for Functionally Graded Materials, Composites: Part B (Engineering), 30(8), 777-832.

17. Pindera, M-J., Aboudi, J., and Arnold, S. M. (1998), Thermomechanical Analysis of Functionally Graded Thermal Barrier Coatings with Different Microstructural Scales, J. American Ceramics Society, 81(6), 1525-36.

18. Berndt, C. C. and Miller, R. A. (1984), Failure Analysis of Plasma-sprayed Thermal Barrier Coatings, NASA TM 8377\%, NASA Lewis Research Center, Cleveland, OH.

19. Brindley, W. J., Miller, R. A., and Aikin, B. J. (1998), Improved Bond-Coat Layers for Thermal-Barrier Coatings, NASA Tech Briefs, August 1998, 63-65. 


\section{APPENDIX}

In outlining the basic structure of the higher-order theory for functionally graded materials, distinction must be made between the global coordinates $x_{1}, x_{2}, x_{3}$ shown in Fig. 2, and the local inplane coordinates $\bar{x}_{2}^{(\beta)}, \bar{x}_{3}^{(\gamma)}$ used to designate position within each subcell $(\beta \gamma)$ of the generic cell $(q, r)$. The local and the global coordinate directions designated by the same subscript are parallel to each other. The subcell designation $(\beta \gamma)$ identifies the subcell's relative position within a given cell along the global $x_{2}, x_{3}$ coordinates. Since there are four subcells in each generic cell, with two subcells along each of the global $x_{2}, x_{3}$ coordinates, the indices $\beta$ and $\gamma$ take on the values 1 or 2 .

\subsection{Thermal Analysis}

Let the functionally graded parallelpiped shown in Fig. 2 be subjected to steady-state temperature or heat flux distributions on its bounding surfaces. Under these circumstances, the heat flux field in the material occupying the subcell $(\beta \gamma)$ of the $(q, r)$ th generic cell, in the region $\left|\bar{x}_{2}^{(\beta)}\right| \leq \frac{1}{2} h_{\beta}^{(q)},\left|\bar{x}_{3}^{(\gamma)}\right| \leq \frac{1}{2} l_{\gamma}^{(r)}$, must satisfy:

$$
\frac{\partial q_{2}^{(\beta \gamma)}}{\partial \bar{x}_{2}^{(\beta)}}+\frac{\partial q_{3}^{(\beta \gamma)}}{\partial \bar{x}_{3}^{(\gamma)}}=0,(\beta, \gamma=1,2)
$$

The components $q_{i}^{(\beta \gamma)}$ of the heat flux vector in this subcell are derived from the temperature field according to:

$$
q_{i}^{(\beta \gamma)}=-k_{i}^{(\beta \gamma)} \frac{\partial T^{(\beta \gamma)}}{\partial \bar{x}_{i}^{(\cdot)}},(i=2,3 ; \text { no sum })
$$

where $k_{i}^{(\beta \gamma)}$ are the coefficients of heat conductivity of the material in the subcell $(\beta \gamma)$, and no summation is implied by repeated Greek letters in the above and henceforth.

The temperature distribution in the subcell $(\beta \gamma)$ of the $(q, r)$ th generic cell, measured with respect to a reference temperature $T_{\text {ref }}$, is denoted by $T^{\left(\beta_{\gamma}\right)}$. This temperature field is approximated by a second order expansion in the local coordinates $\bar{x}_{2}^{(\beta)}, \bar{x}_{3}^{(\gamma)}$ as follows:

$$
T^{(\beta \gamma)}=T_{(00)}^{(\beta \gamma)}+\bar{x}_{2}^{(\beta)} T_{(10)}^{(\beta \gamma)}+\bar{x}_{3}^{(\gamma)} T_{(01)}^{(\beta \gamma)}+\frac{1}{2}\left(3 \bar{x}_{2}^{(\beta) 2}-\frac{h_{\beta}^{(q) 2}}{4}\right) T_{(20)}^{(\beta \gamma)}+\frac{1}{2}\left(3 \bar{x}_{3}^{(\gamma) 2}-\frac{l_{\gamma}^{(r) 2}}{4}\right) T_{(02)}^{(\beta \gamma)}
$$

where $T_{(00)}^{(\beta \gamma)}$, which is the temperature at the center of the subcell, and $T_{(m n)}^{(\beta \gamma)}(m, n=0,1$, or 2 with $m+n \leqq 2)$ are unknown coefficients which are determined from conditions that will be outlined subsequently.

Given the five unknown quantities associated with each subcell (i.e., $T_{(00)}^{(\beta \gamma)}, \ldots, T_{(02)}^{(\beta \gamma)}$ ) and four subcells within each generic cell, $20 N_{q} N_{r}$ unknown quantities must be determined for a composite with $N_{q}$, and $N_{r}$ rows and columns of cells containing arbitrarily specified materials. These quantities are determined by first satisfying the heat conduction equation, as well as the first and second moment of this equation in each subcell in a volumetric sense in view of the employed temperature field approximation. Subsequently, continuity of heat flux and temperature is imposed in an average sense at the interfaces separating adjacent subcells, as well as neighboring cells. Fulfillment of these field equations and continuity conditions, together with the imposed thermal boundary conditions on the bounding surfaces of the composite, provides the necessary $20 N_{q} N_{r}$ equations for 
the $20 N_{q} N_{r}$ unknown coefficients $T_{(m n)}^{(\beta \gamma)}$ in the temperature field expansion in each $(\beta \gamma)$ subcell. The final form of this system of equations is symbolically represented below

$$
\kappa \mathbf{T}=\mathbf{t}
$$

where the structural thermal conductivity matrix $\kappa$ contains information on the geometry and thermal conductivities of the individual subcells $(\beta \gamma)$ in the $N_{q} N_{r}$ cells spanning the $x_{2}$ and $x_{3}$ directions, the thermal coefficient vector $T$ contains the unknown coefficients that describe the temperature field in each subcell, i.e.,

$$
\mathbf{T}=\left[\mathbf{T}_{11}^{(11)}, \ldots, \mathbf{T}_{N_{q} N_{r}}^{(22)}\right]
$$

where

$$
\mathbf{T}_{q r}^{(\beta \gamma)}=\left[T_{(00)}, T_{(10)}, T_{(01)}, T_{(20)}, T_{(02)}\right]_{q r}^{(\beta \gamma)}
$$

and the thermal force vector $\mathbf{t}$ contains information on the boundary conditions.

\subsection{Mechanical Analysis}

Given the temperature field generated by the applied surface temperatures and/or heat fluxes obtained in the preceding section, we proceed to determine the resulting displacement and stress fields. This is carried out for arbitrary mechanical loading, consistent with global equilibrium requirements, applied to the surfaces of the composite.

The stress field in the subcell $(\beta \gamma)$ of the $(q, r)$ th generic cell generated by the given temperature field must satisfy the equilibrium equations

$$
\frac{\partial \sigma_{2 j}^{(\beta \gamma)}}{\partial \bar{x}_{2}^{(\beta)}}+\frac{\partial \sigma_{3 j}^{(\beta \gamma)}}{\partial \bar{x}_{3}^{(\gamma)}}=0,(j=2,3)
$$

The components of the stress tensor, assuming that the material occupying the subcell $(\beta \gamma)$ of the $(q, r)$ th generic cell is isotropic, are related to the strain components through the familiar Hooke's law:

$$
\sigma_{i j}^{(\beta \gamma)}=2 \mu^{(\beta \gamma)} \varepsilon_{i j}^{(\beta \gamma)}+\lambda^{(\beta \gamma)} \varepsilon_{k k}^{(\beta \gamma)} \delta_{i j}-2 \mu^{(\beta \gamma)} \varepsilon_{i j}^{i n(\beta \gamma)}-\sigma_{i j}^{T(\beta \gamma)}
$$

where $\lambda^{(\beta \gamma)}$ and $\mu^{(\beta \gamma)}$ are the Lamé's constants of the material filling the given subcell $(\beta \gamma), \varepsilon_{i j}^{i n(\beta \gamma)}$ are the inelastic strain components, and $\sigma_{i j}^{T(\beta \gamma)}$ is the thermal stress consisting of the products of the stiffness tensor components, thermal expansion coefficients and the temperature change. The components of the strain tensor in the individual subcells are obtained from the strain-displacement relations.

The displacement field in the subcell $(\beta \gamma)$ of the $(q, r)$ th generic cell is approximated by a second-order expansion in the local coordinates $\bar{x}_{2}^{(\beta)}$, and $\bar{x}_{3}^{(\gamma)}$ as follows:

$$
\begin{gathered}
u_{1}^{(\beta \gamma)}=x_{1} \bar{\varepsilon}_{11} \\
u_{2}^{(\beta \gamma)}=W_{2(00)}^{(\beta \gamma)}+\bar{x}_{2}^{(\beta)} W_{2(10)}^{(\beta \gamma)}+\bar{x}_{3}^{(\gamma)} W_{2(01)}^{(\beta \gamma)}+\frac{1}{2}\left(3 \bar{x}_{2}^{(\beta) 2}-\frac{h_{\beta}^{(q) 2}}{4}\right) W_{2(20)}^{(\beta \gamma)}+\frac{1}{2}\left(3 \bar{x}_{3}^{(\gamma) 2}-\frac{l_{\gamma}^{(r) 2}}{4}\right) W_{2(02)}^{(\beta \gamma)} \\
u_{3}^{(\beta \gamma)}=W_{3(00)}^{(\beta \gamma)}+\bar{x}_{2}^{(\beta)} W_{3(10)}^{(\beta \gamma)}+\bar{x}_{3}^{(\gamma)} W_{3(01)}^{(\beta \gamma)}+\frac{1}{2}\left(3 \bar{x}_{2}^{(\beta) 2}-\frac{h_{\beta}^{(q) 2}}{4}\right) W_{3(20)}^{(\beta \gamma)}+\frac{1}{2}\left(3 \bar{x}_{3}^{(\gamma) 2}-\frac{l_{\gamma}^{(r) 2}}{4}\right) W_{3(02)}^{(\beta \gamma)}
\end{gathered}
$$


where $W_{i(00)}^{(\beta \gamma)}$, which are the displacements at the center of the subcell, and the higher-order terms $W_{i(m n)}^{(\beta \gamma)}(i=2,3)$ must be determined from conditions similar to those employed in the thermal problem. In this case, there are 40 unknown coefficients $W_{i(m n)}^{(\beta \gamma)}$ in a generic cell $(q, r)$. The determination of these coefficients parallels that of the thermal problem. Here, the heat conduction equation is replaced by the two equilibrium equations, and the continuity of tractions and displacements at the various interfaces replaces the continuity of heat fluxes and temperature. Finally, the boundary conditions involve the appropriate mechanical quantities.

Application of the above equations and conditions in a volumetric and average sense, respectively, produces a system of $40 N_{q} N_{r}$ algebraic equations in the unknown coefficients $W_{i(m n)}^{(\beta \gamma)}$. The final form of this system of equations is symbolically represented by

$$
\mathbf{K U}=\mathbf{f}+\mathbf{g}
$$

where the structural stiffness matrix $\mathbf{K}$ contains information on the geometry and thermomechanical properties of the individual subcells $(\beta \gamma)$ within the cells comprising the functionally graded composite, the displacement coefficient vector $\mathbf{U}$ contains the unknown coefficients that describe the displacement field in each subcell, i.e.,

$$
\mathbf{U}=\left[\mathbf{U}_{11}^{(11)}, \ldots, \mathbf{U}_{N_{\mathrm{q}} N_{r}}^{(22)}\right]
$$

where

$$
\mathrm{U}_{q r}^{(\beta \gamma)}=\left[W_{i(00)}, W_{i(10)}, W_{i(01)}, W_{i(20)}, W_{i(02)}\right]_{q \tau}^{(\beta \gamma)} \quad(i=2,3)
$$

and the mechanical force vector $\mathbf{f}$ contains information on the boundary conditions and the thermal loading effects generated by the applied temperature. In addition, the inelastic force vector $\mathbf{g}$ appearing on the right hand side of eqn (A10) contains the inelastic effects given in terms of the integrals of the inelastic strain distributions that are represented by the coefficients $R_{i j(m, n)}^{(\beta \gamma)}$ defined below

$$
R_{i j(m, n)}^{(\beta \gamma)}=\mu^{(\beta \gamma)} \Lambda_{(m n)} \int_{-1}^{+1} \int_{-1}^{+1} \varepsilon_{i j}^{i n(\beta \gamma)} P_{m}\left(\zeta_{2}^{(\beta)}\right) P_{n}\left(\zeta_{3}^{(\gamma)}\right) d \zeta_{2}^{(\beta)} d \zeta_{3}^{(\gamma)}
$$

where

$$
\Lambda_{(m n)}=\frac{1}{4} \sqrt{(1+2 m)(1+2 n)}
$$

and the Legandre polynomials $P\left(\zeta_{i}^{(\cdot)}\right)$ are functions of the non-dimensionalized variables $\zeta_{i}^{(\cdot)}$ 's, defined in the interval $-1 \leqq \zeta_{i}^{(\cdot)} \leqq+1$, which are given in terms of the local subcell coordinates as follows: $\zeta_{2}^{(\beta)}=\bar{x}_{2}^{(\beta)} /\left(h_{\beta}^{(q)} / 2\right)$, and $\zeta_{3}^{(\gamma)}=\bar{x}_{3}^{(\gamma)} /\left(l_{\gamma}^{(r)} / 2\right)$. These integrals depend implicitly on the elements of the displacement coefficient vector $\mathbf{U}$, requiring an incremental solution of eqn (A10) at each point along the loading path. 


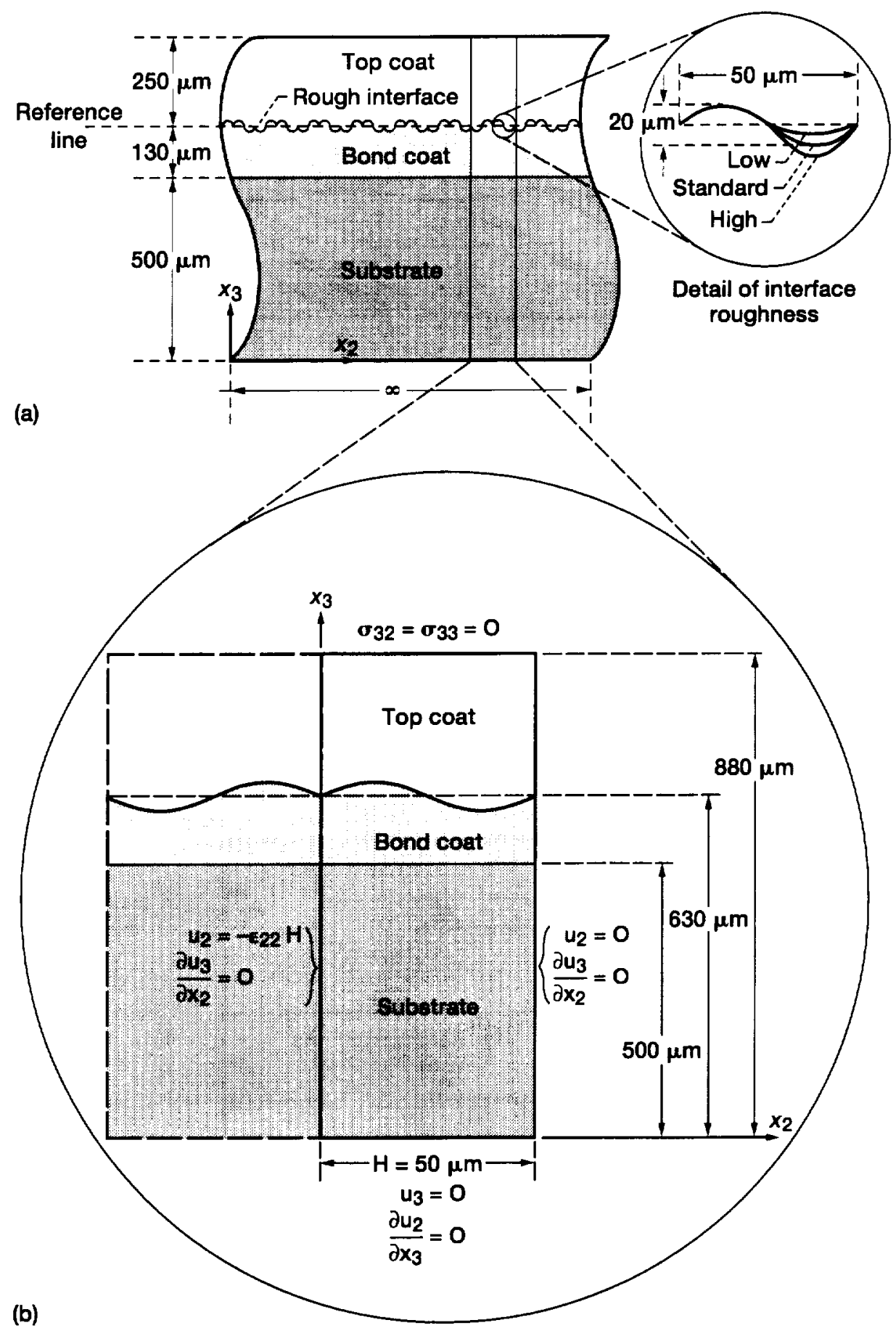

Figure 1.-(a) A TBC system with different degrees of top coat/bond coat interfacial roughness, (b) repeating cross-section element of the TBC system with indicated boundary conditions. 


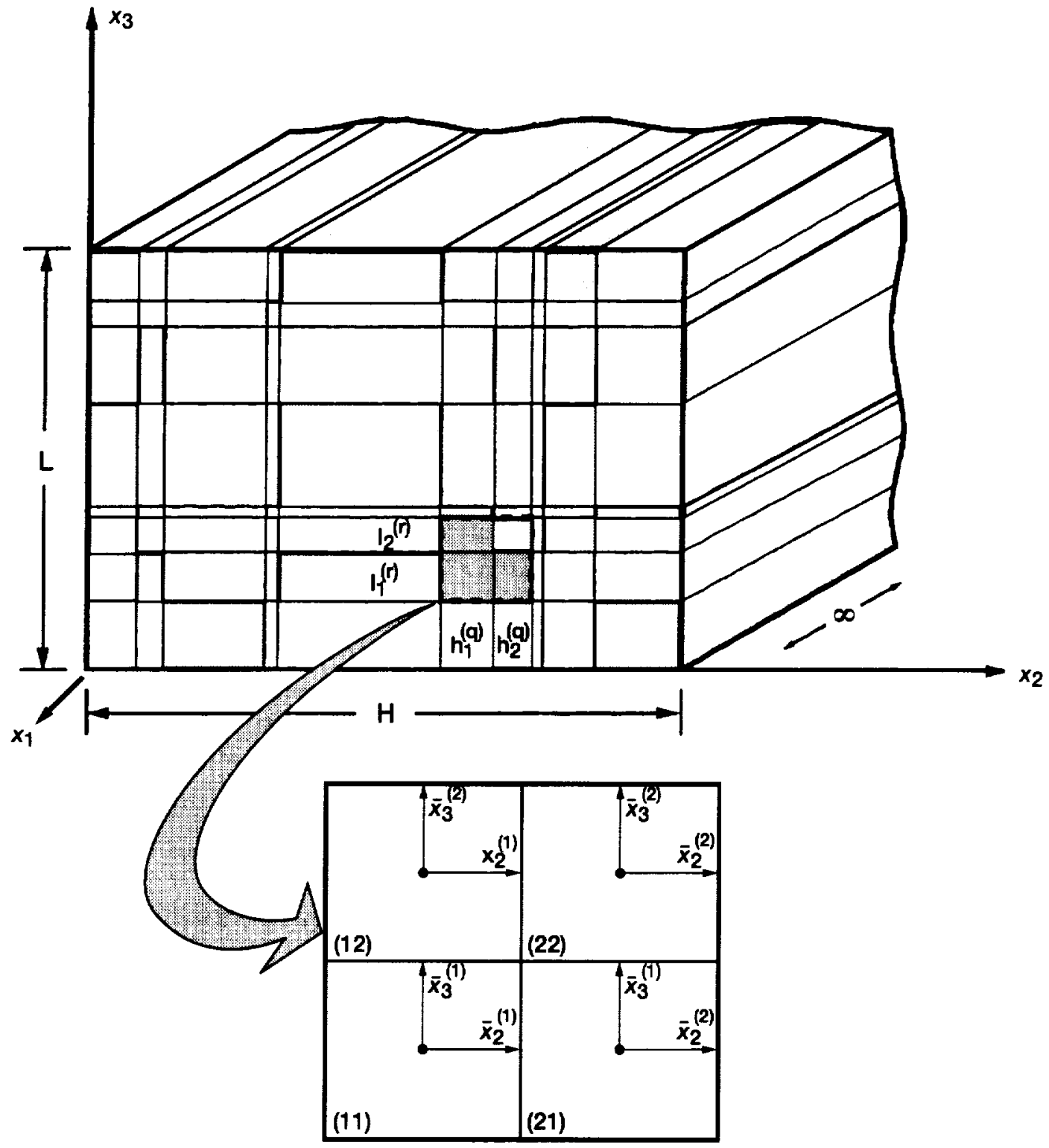

Generic cell $(q, r)$

Figure 2.-A geometric model of a material functionally graded in the $x_{2}-x_{3}$ plane illustrating the volume discretization employed in HOTFGM-2D. 

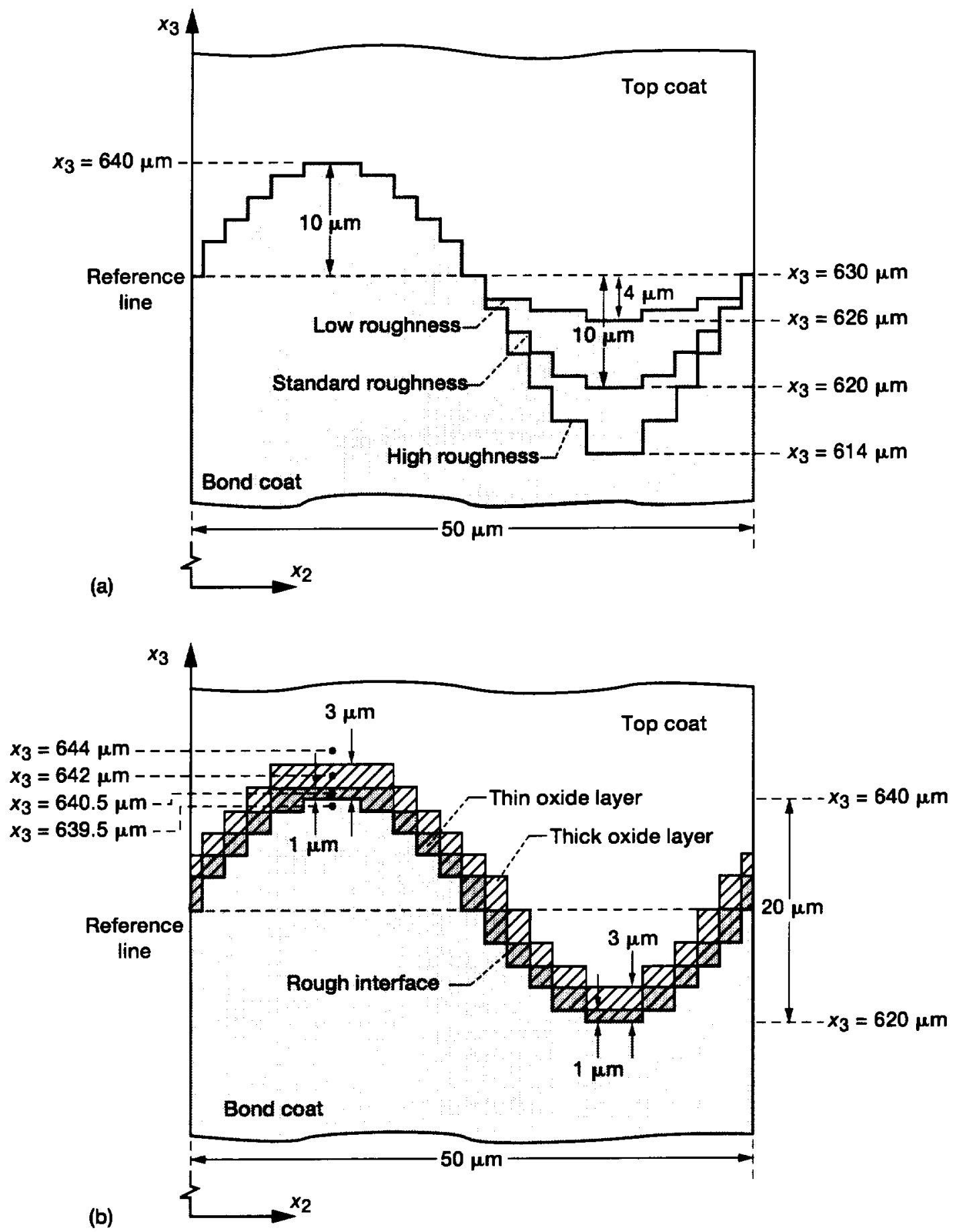

Figure 3.-Volume discretization of the wavy interface region: (a) low, standard and high interfacial roughness; (b) standard interface roughness with thin and thick oxide layer thickness. 


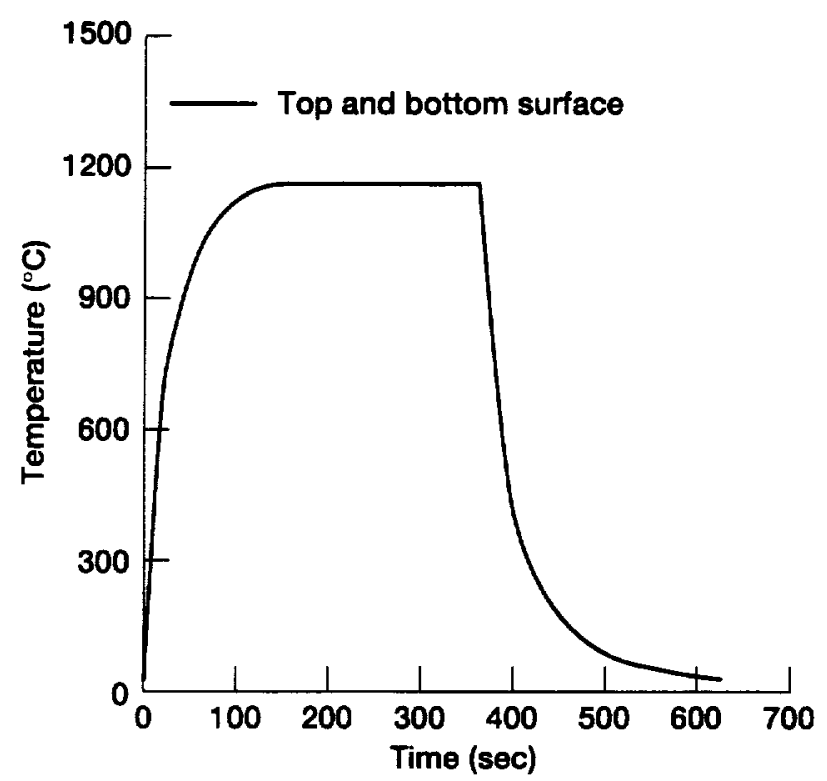

Figure 4.-Thermal loading history. 

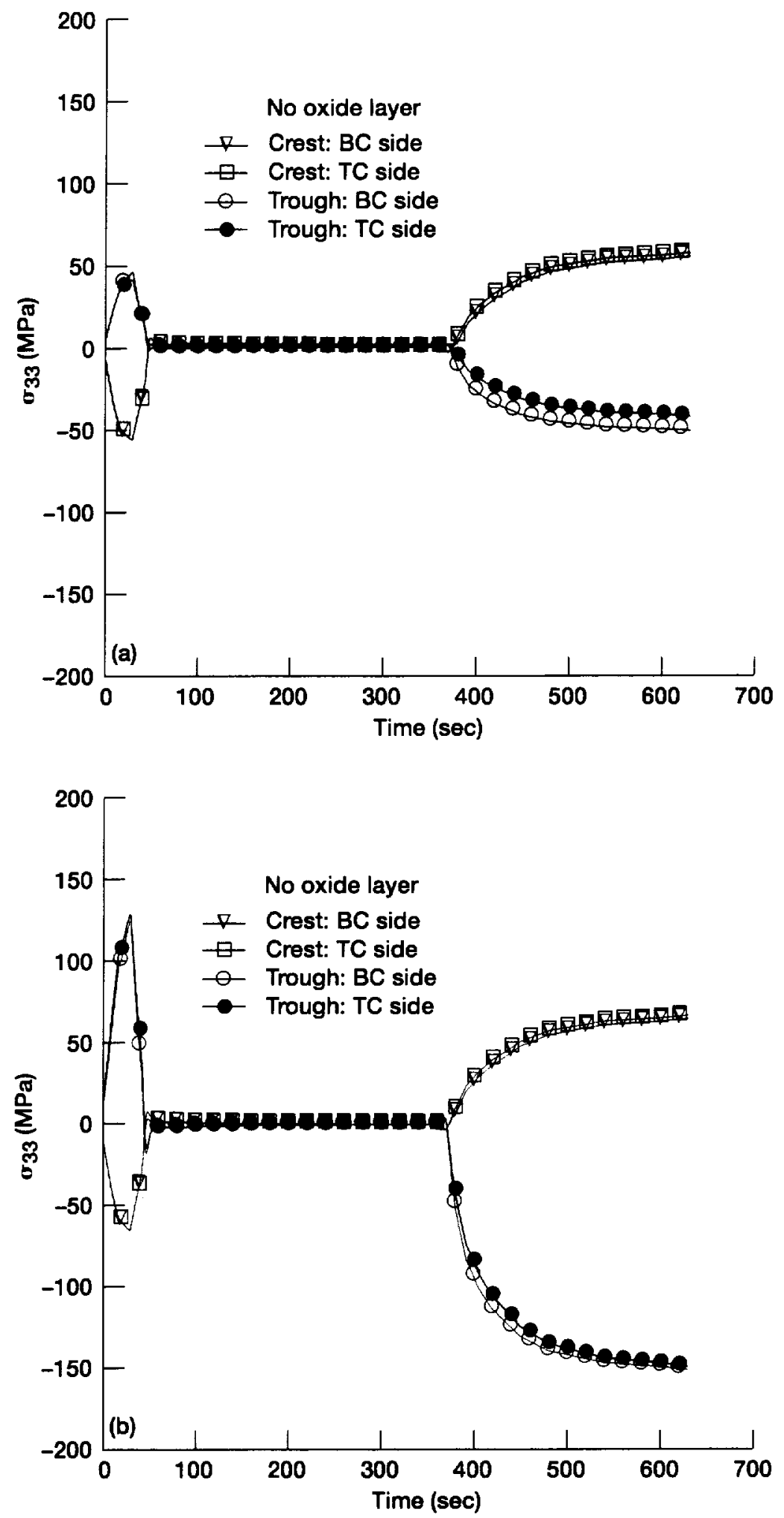

Figure 5.-Interfacial through-thickness stress continuity as a function of time across the crest and trough of rough interfaces without an oxide layer: (a) low interfacial roughness; (b) high interfacial roughness. 

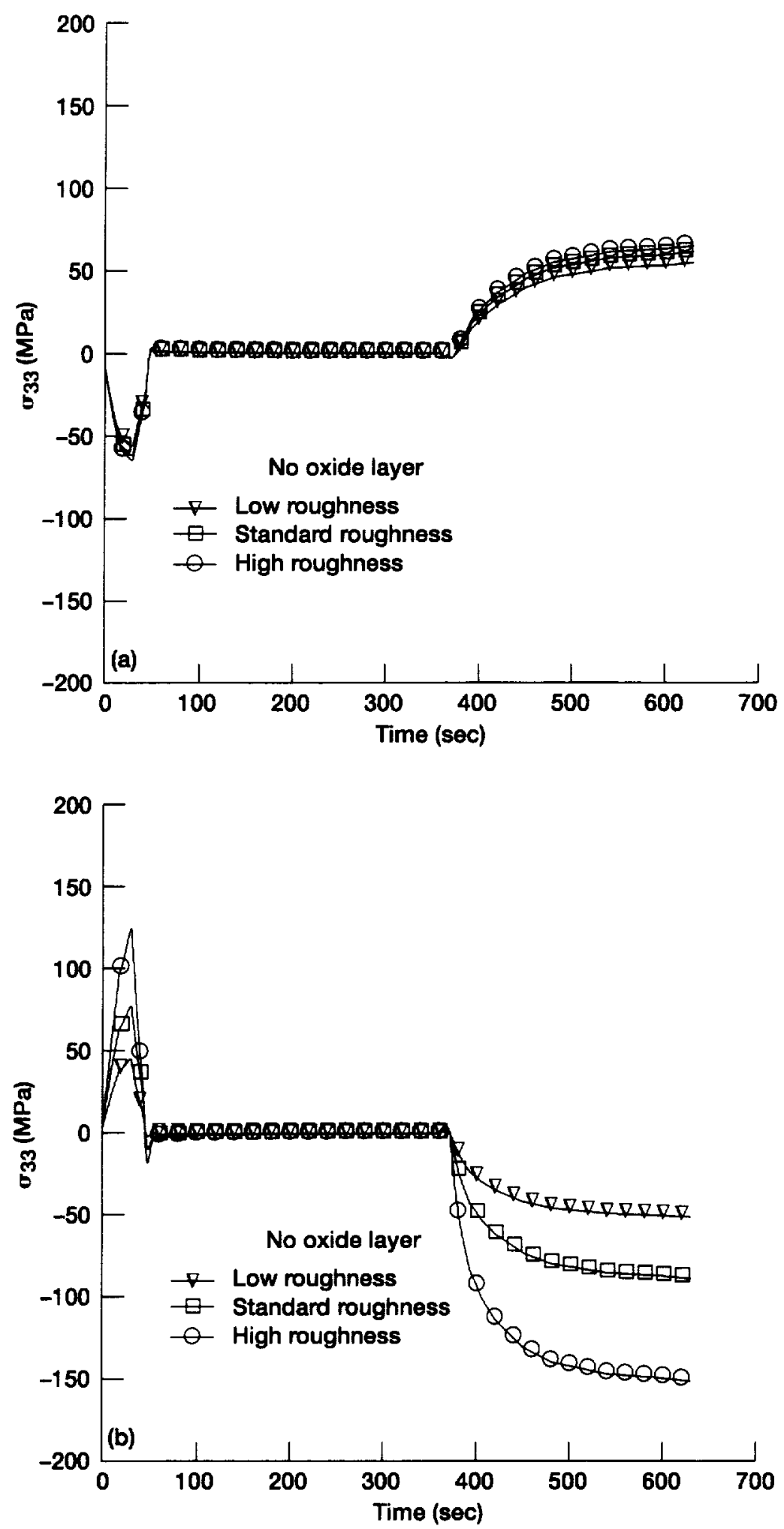

Figure 6.-Effect of interfacial roughness on the through-thickness stress evolution with time at the bond coat/top coat interface: (a) crest location; (b) trough location. 


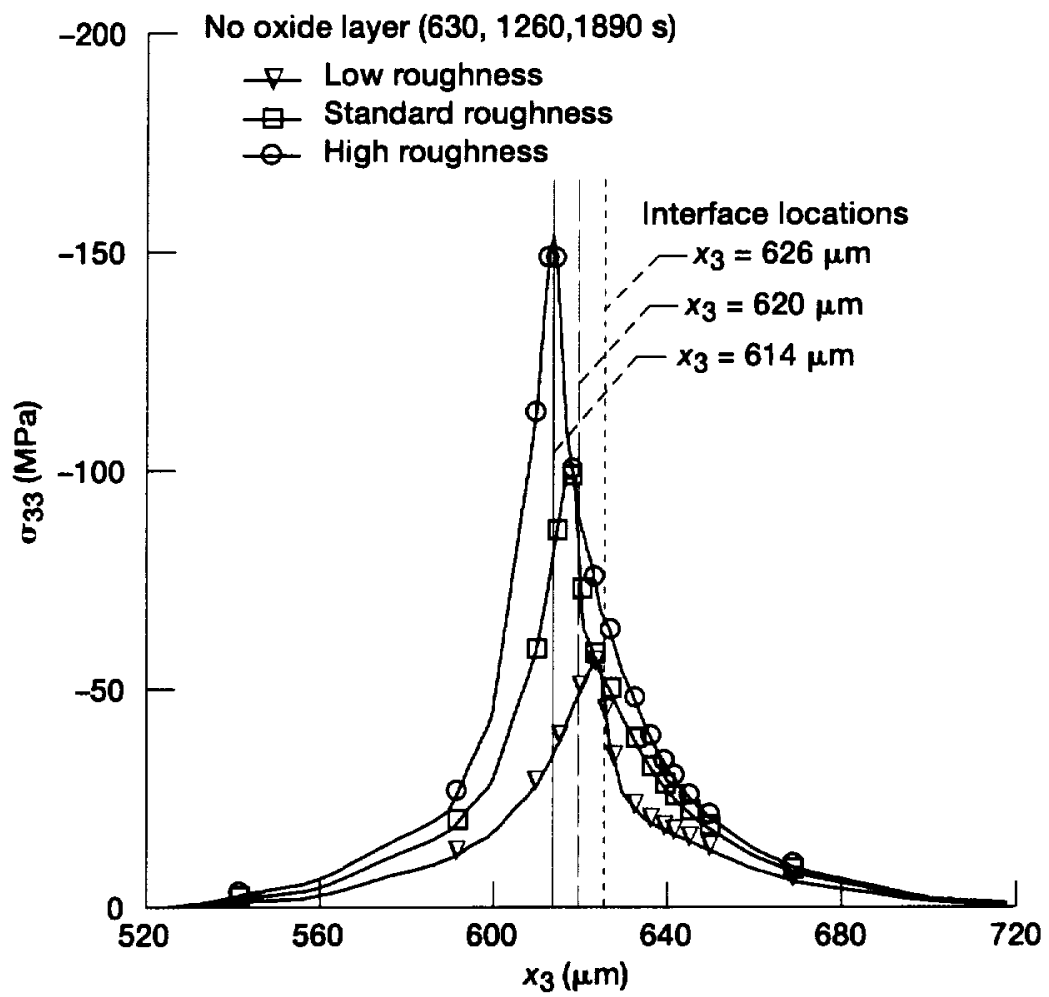

Figure 7.-Effect of interfacial roughness on the through-thickness stress distributions at the end of each thermal cycle $(630,1260$, and 1890 seconds) along vertical cross section (in the $x_{3}$ direction) passing through the trough. Top coat/bond coat interface locations are given by $x_{3}=626 \mu \mathrm{m}$ (low roughness, dotted line), $x_{3}=620 \mu \mathrm{m}$ (standard roughness, dashed line), $x_{3}=614 \mu \mathrm{m}$ (high roughness, solid line). 


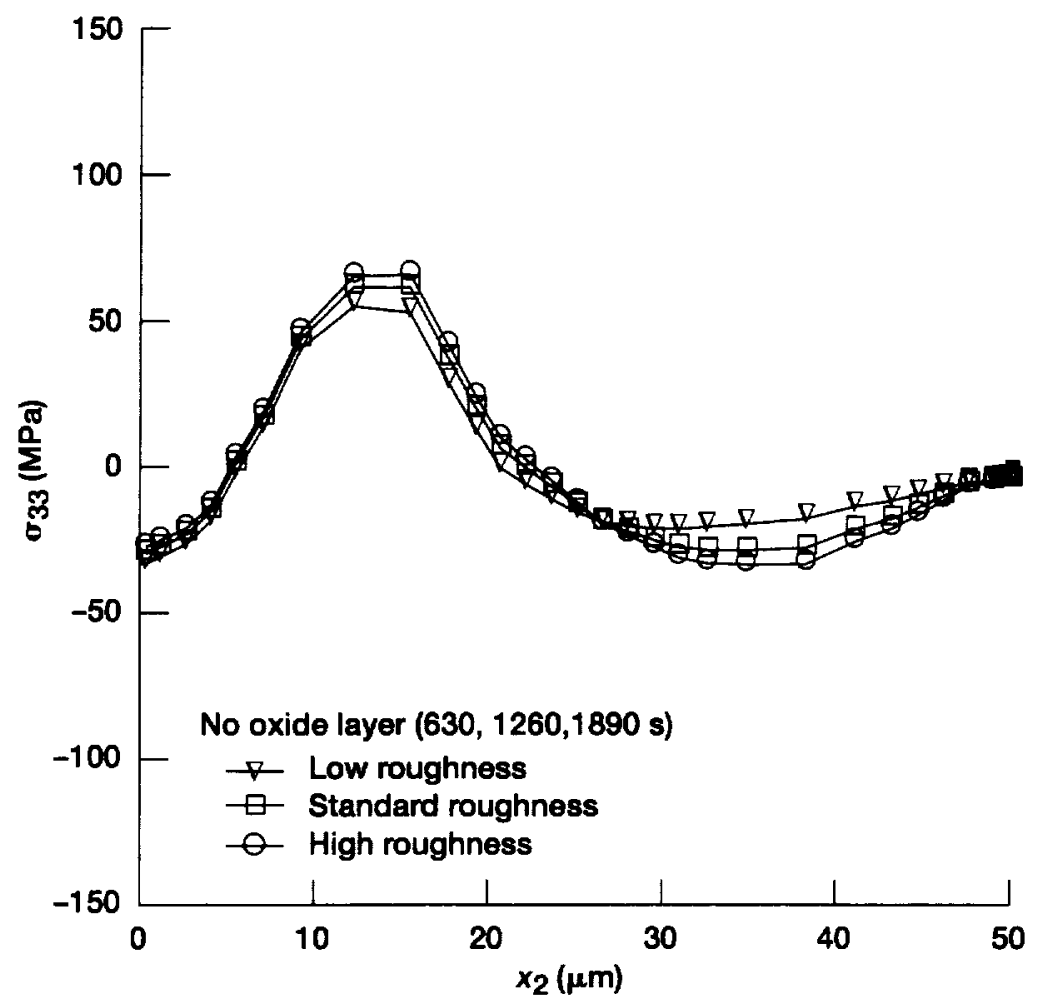

Figure 8.-Effect of interfacial roughness on the through-thickness stress distributions at the end of each thermal cycle $(630,1260$, and 1890 seconds) along horizontal cross section (in the $x_{2}$ direction) passing through the crest of the bond coat/top coat interface. 

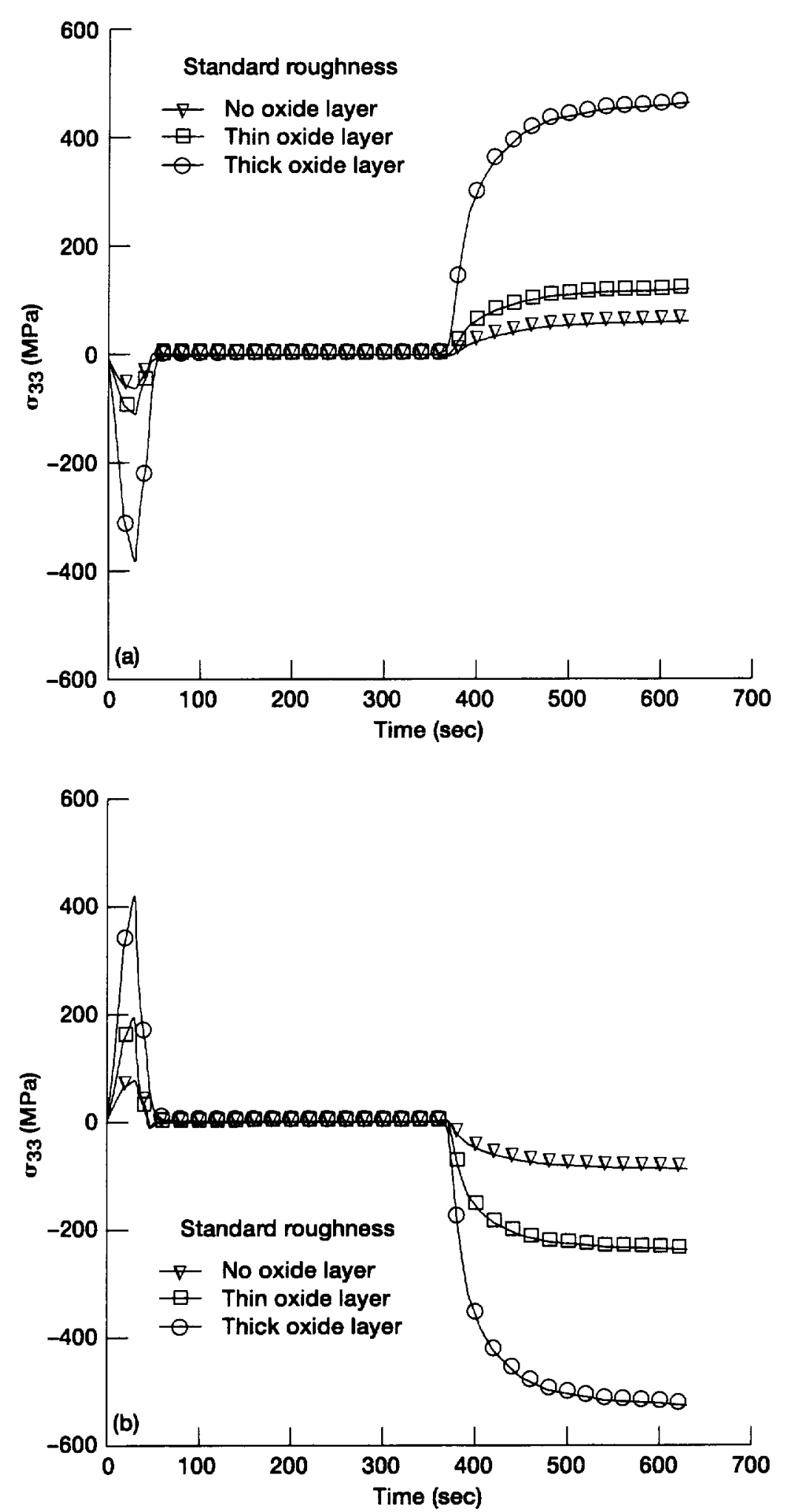

Figure 9.-Effect of oxide layer thickness on the through-thickness stress evolution with time on the bond coat side of the standard interface at the crest (a) and trough (b). 

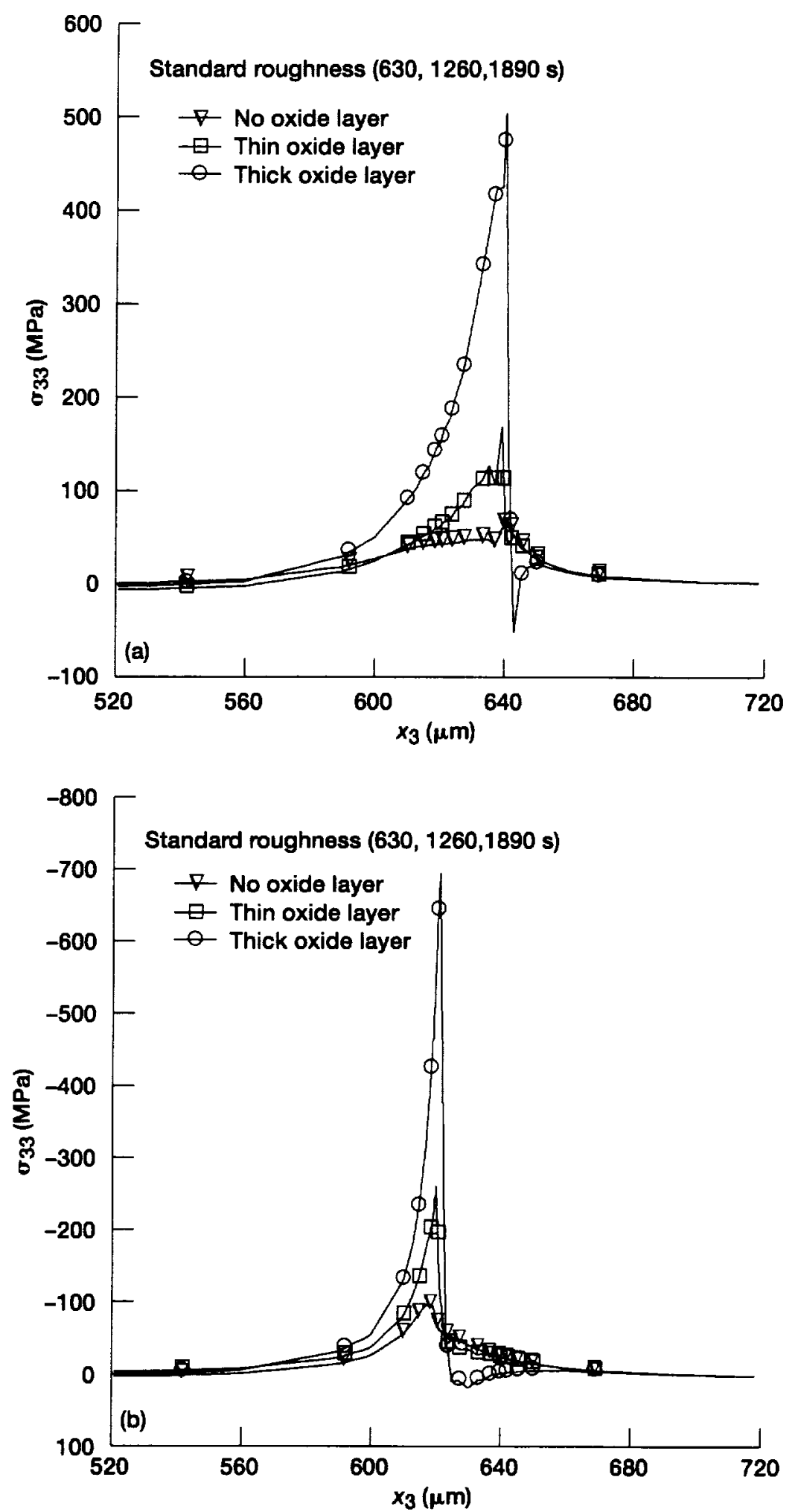

Figure 10.-Effect of oxide layer thickness on the through-thickness stress distributions at the end of each thermal cycle $(630,1260$, and 1890 seconds) along vertical cross section (in the $x_{3}$ direction) passing through the crest, $x_{3}=640 \mu \mathrm{m}$ (a) and trough, $x_{3}=620 \mu \mathrm{m}$ (b) of the standard interface. 

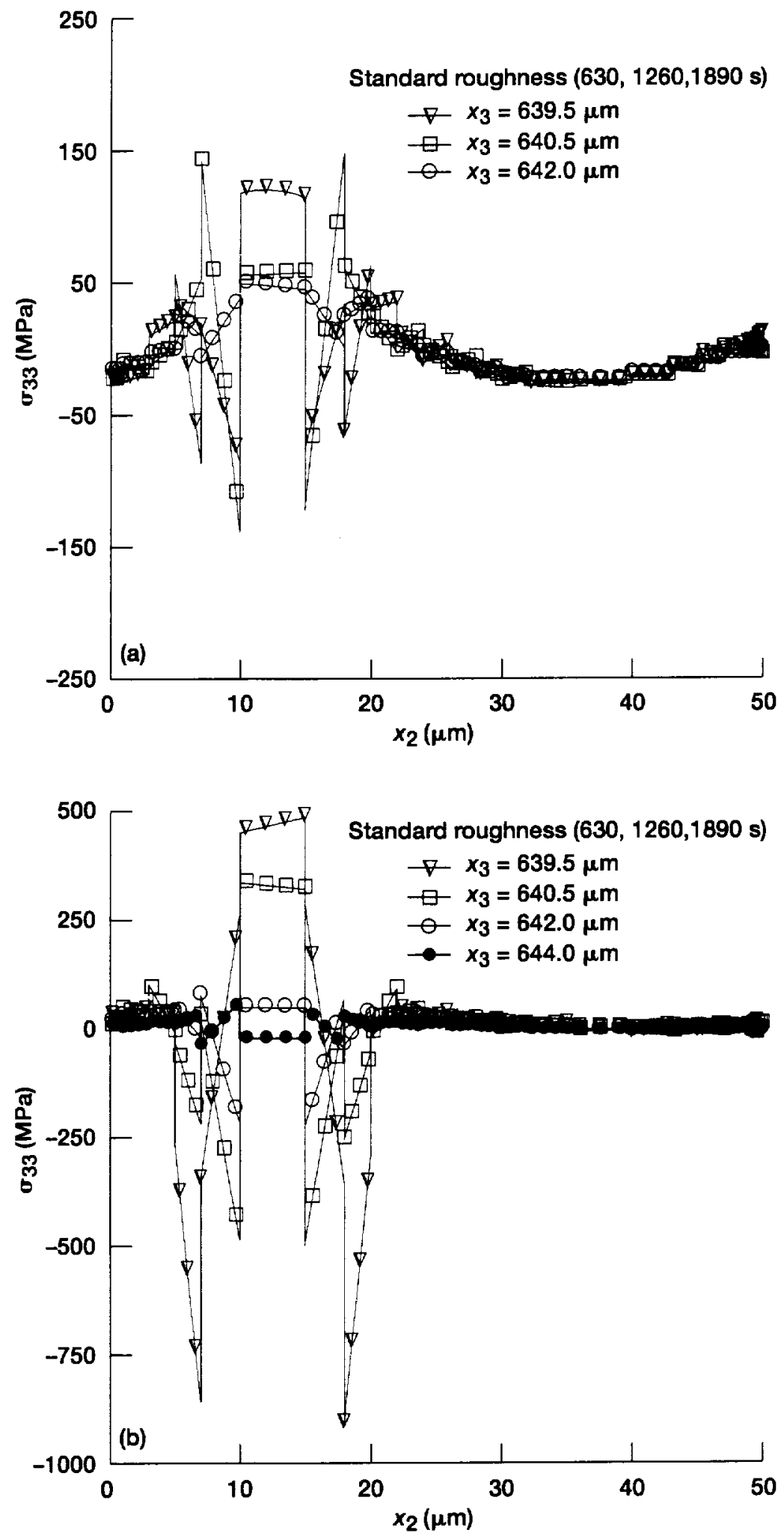

Figure 11.-Effect of oxide layer thickness on the through-thickness stress distributions at the end of each thermal cycle $(630,1260$, and 1890 seconds) along horizontal cross section (in the $x_{2}$ direction) passing below, through and above the bond coat/oxide layer/top coat regions at the crest of the standard interface: (a) thin oxide layer; (b) thick oxide layer. 


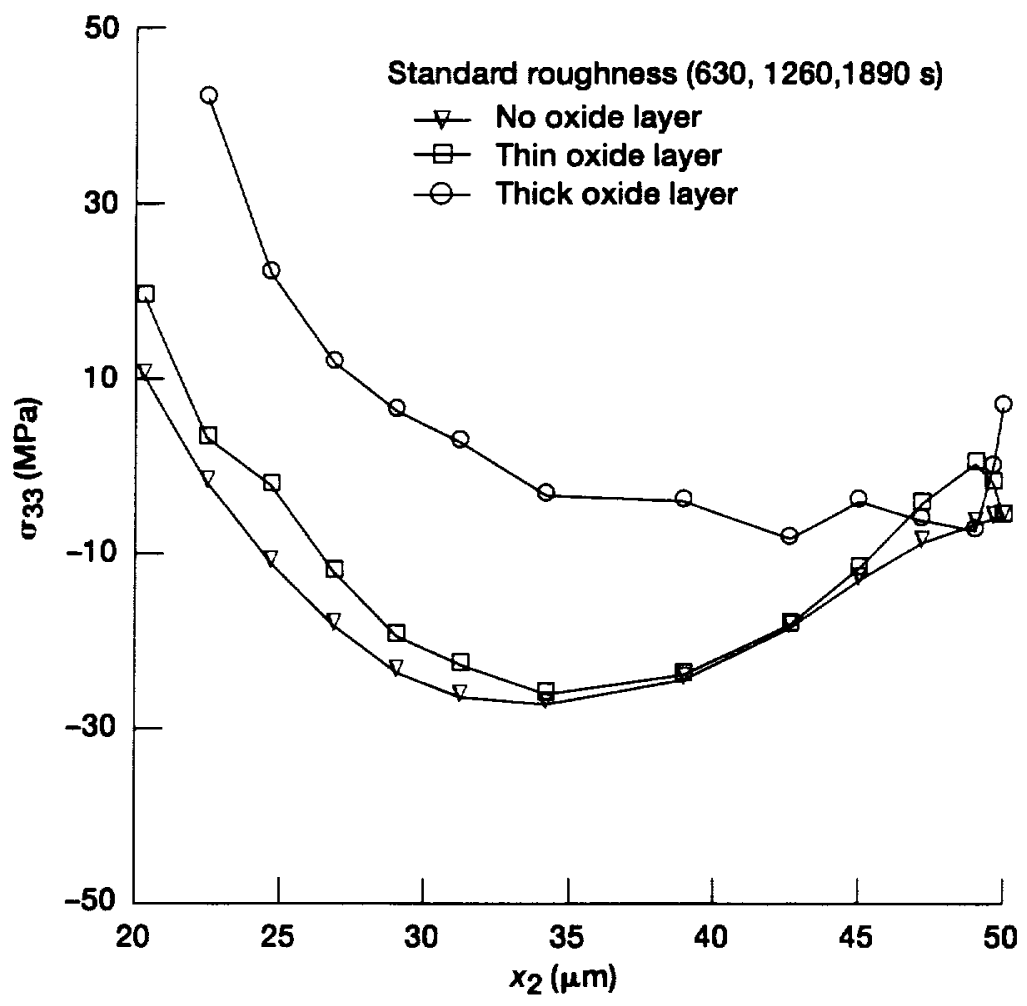

Figure 12.-Comparison of the horizontal through-thickness stress distributions at the elevation $x_{3}=640.5 \mu \mathrm{m}$ for the standard interface without and with thin and thick oxide layers. 

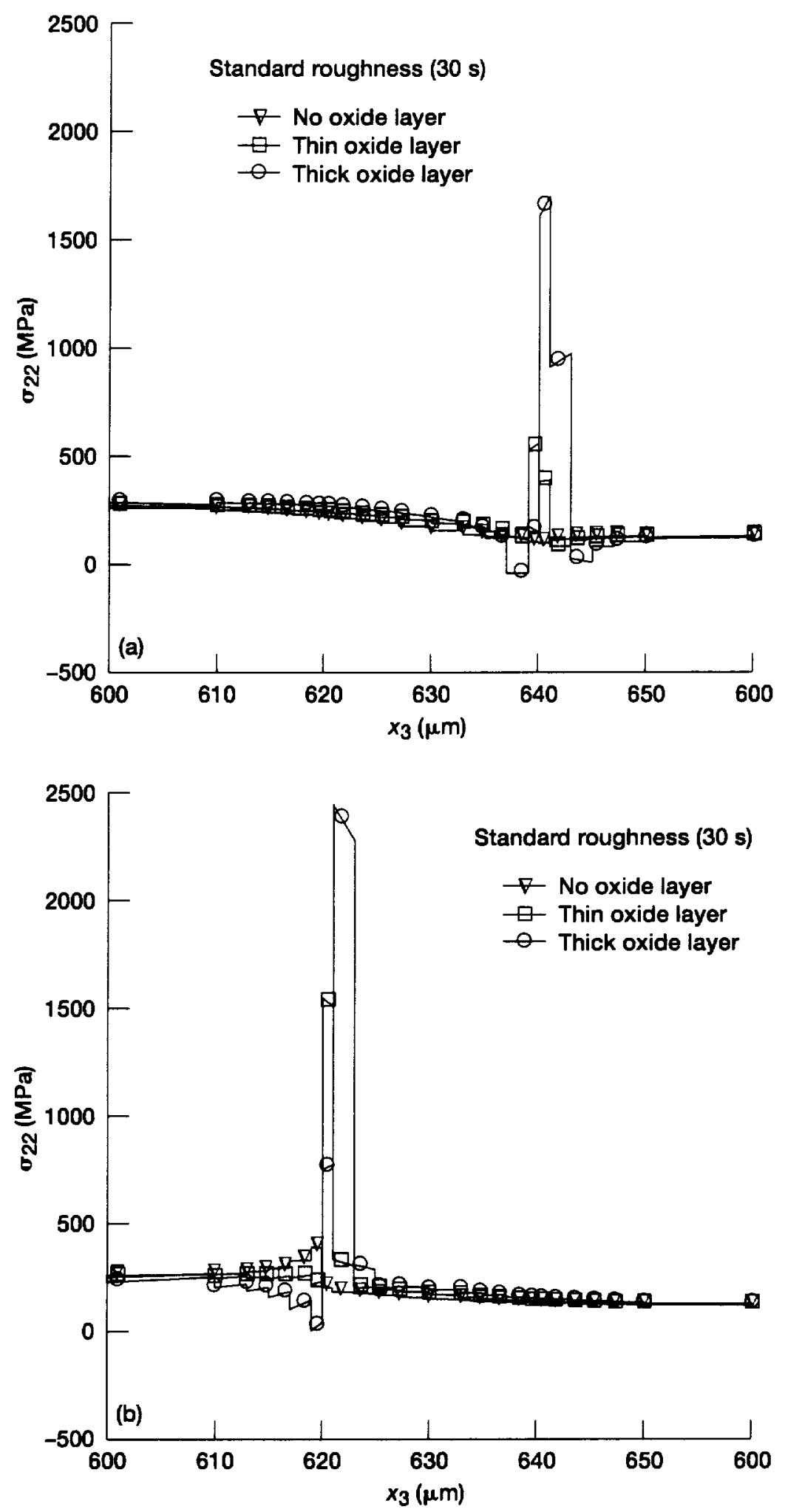

Figure 13.-Effect of oxide layer thickness on transverse stress distributions during the initial heatup ( 30 seconds) along vertical cross section (in the $x_{3}$ direction) passing through the crest (a), and trough (b) of the standard interface. 

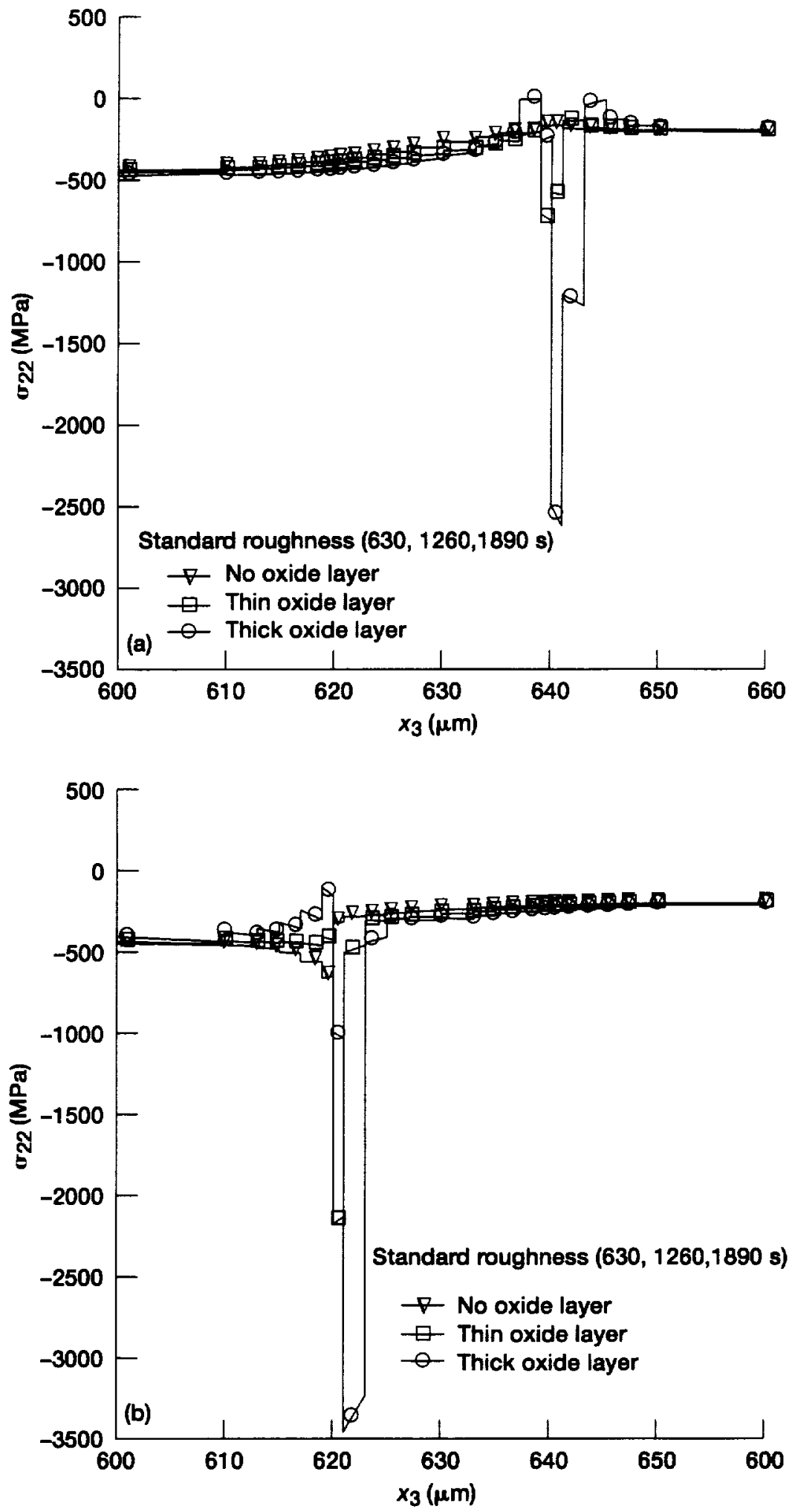

Figure 14.-Effect of oxide layer thickness on the transverse stress distributions at the end of each thermal cycle $(630,1260$, and 1890 seconds) along vertical cross section (in the $x_{3}$ direction) passing through the crest (a) and trough (b) of the standard interface. 


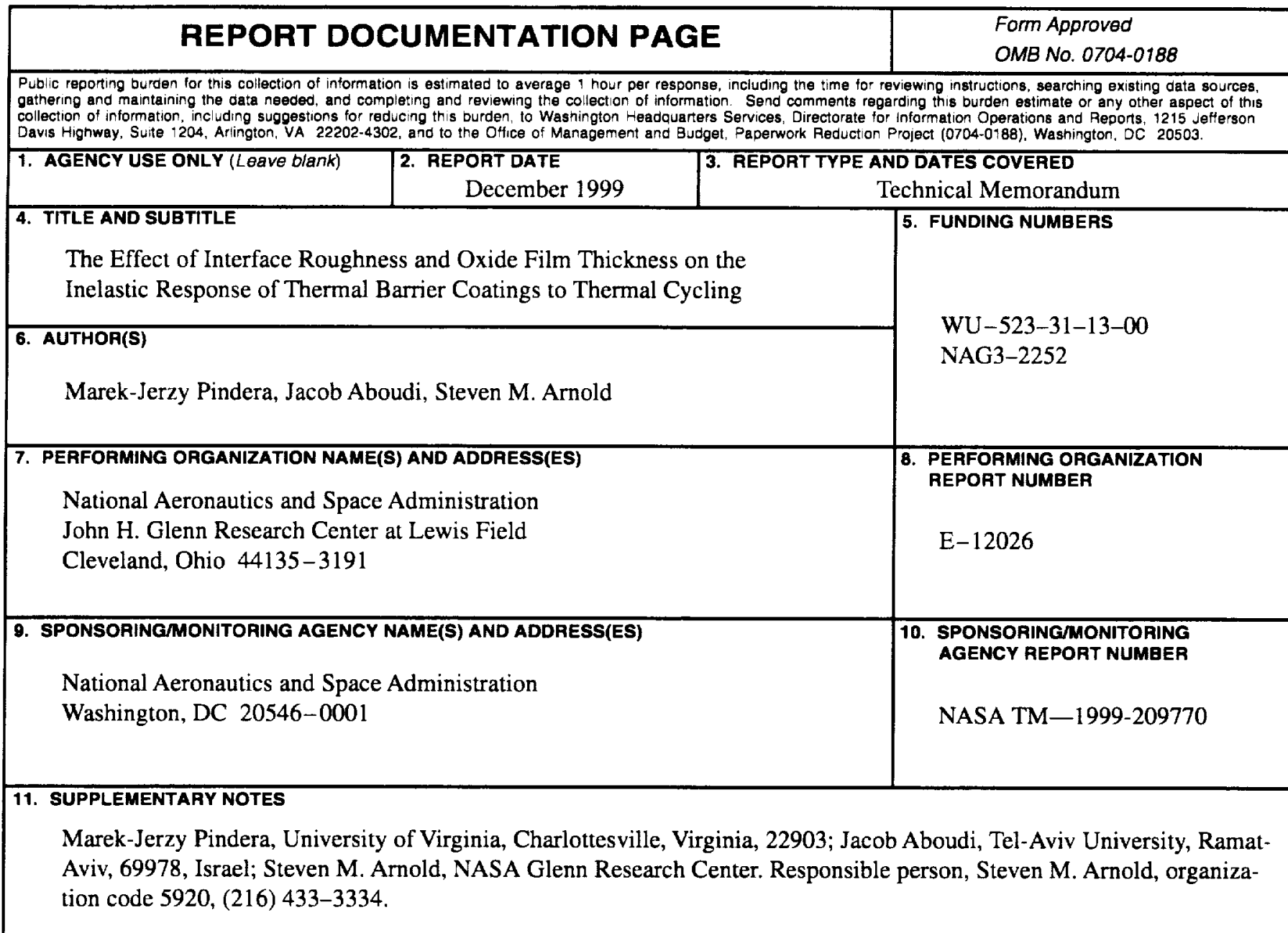

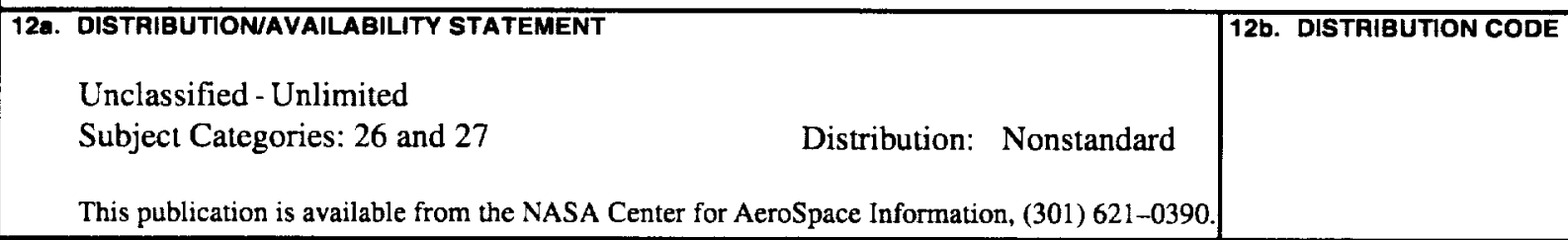

13. ABSTRACT (Maximum 200 words)

The effects of interfacial roughness and oxide film thickness on thermally-induced stresses in plasma-sprayed thermal barrier coatings subjected to thermal cycling are investigated using the recently developed higher-order theory for functionally graded materials. The higher-order theory is shown to be a viable alternative to the finite-element approach, capable of modeling different interfacial roughness architectures in the presence of an aluminum oxide layer and capturing the high stress gradients that occur at the top coat/bond coat interface. The oxide layer thickness is demonstrated to have a substantially greater effect on the evolution of residual stresses than local variations in interfacial roughness. Further, the location of delamination initiation in the top coat is predicted to change with increasing oxide layer thickness. This result can be used to optimize the thickness of a pre-oxidized layer introduced at the top coat/bond coat interface in order to enhance TBC durability as suggested by some researchers. The results of our investigation also support a recently proposed hypothesis regarding delamination initiation and propagation in the presence of an evolving bond coat oxidation, while pointing to the importance of interfacial roughness details and specimen geometry in modeling this phenomenon.

\begin{tabular}{|c|c|c|}
\hline \multicolumn{3}{|l|}{ 14. SUBJECT TERMS } \\
\hline $\begin{array}{l}\text { 17. SECURITY CLASSIFICATION } \\
\text { OF REPORT } \\
\text { Unclassified }\end{array}$ & $\begin{array}{l}\text { 18. SECURITY CLASSIFICATION } \\
\text { OF THIS PAGE } \\
\text { Unclassified }\end{array}$ & $\begin{array}{l}\text { 19. SECURITY CLASSIFICATION } \\
\text { OF ABSTRACT } \\
\text { Unclassified }\end{array}$ \\
\hline
\end{tabular}

NSN 7540-01-280-5500 